REVIEW ARTICLE

\title{
Acquired immune heterogeneity and its sources in human helminth infection
}

\author{
C. D. BOURKE*, R. M. MAIZELS and F. MUTAPI \\ Institute of Immunology and Infection Research, University of Edinburgh, Ashworth Laboratories, West Mains Road, \\ EH9 $39 T$
}

(Received 12 Fuly 2010; revised 18 Fuly 2010; accepted 18 Fuly 2010; first published online 15 October 2010)

\begin{abstract}
SUMMARY
Similarities in the immunobiology of different parasitic worm infections indicate that co-evolution of humans and helminths has shaped a common anti-helminth immune response. However, recent in vitro and immuno-epidemiological studies highlight fundamental differences and plasticity within host-helminth interactions. 'The 'trade-off' between immunity and immunopathology inherent in host immune responses occurs on a background of genetic polymorphism, variable exposure patterns and infection history. For the parasite, variation in life-cycle and antigen expression can influence the effector responses directed against them. This is particularly apparent when comparing gastrointestinal and tissuedwelling helminths. Furthermore, insights into the impact of anti-helminthic treatment and co-infection on acquired immunity suggest that immune heterogeneity arises not from hosts and parasites in isolation, but also from the environment in which immune responses develop. Large-scale differences observed in the epidemiology of human helminthiases are a product of complex host-parasite-environment interactions which, given potential for exposure to parasite antigens in utero, can arise even before a parasite interacts with its human host. This review summarizes key differences identified in human acquired immune responses to nematode and trematode infections of public health importance and explores the factors contributing to these variations.
\end{abstract}

Key words: heterogeneity, helminth, human, nematode, trematode, schistosome, immune response.

\section{INTRODUCTION}

Over a third of the human population is currently infected by one or more species of parasitic helminth (Hotez et al. 2008). Chronically-infected hosts must strike a balance between anti-parasite protective responses and limiting immune-mediated pathology (Hoffmann et al. 2002), whilst parasites have developed strategies to prolong intra-host survival and fecundity. Throughout their co-evolutionary history these forces, as often in concert as in opposition, have driven diversity in both parasites (Maizels et al. 2001) and the genetics of the host immune response (Fumagalli et al. 2009; Maizels, 2009), the latter especially evident in the human population. Experimental models are invaluable in mechanistic studies of helminth-induced immune responses in vivo; however, reductionist laboratory models inevitably seek to minimize variation in the host, the context of infection and polymorphism in the parasite itself. Moreover, integral differences in the immune

* Corresponding author: Institute of Immunology and Infection Research, University of Edinburgh, Ashworth Laboratories, West Mains Road, Edinburgh, EH9 3JT. Tel: + 44 (0)131 6505445. E-mail: C.D.Bourke@sms.ed. ac.uk systems of different host species (Mestas and Hughes, 2004) and the inability of many anthropophilic helminths to naturally infect laboratory animals mean that current experimental models do not reflect the complexity of human helminth immunobiology. Most importantly, models cannot easily replicate the major sources of human immune heterogeneity such as parasite transmission dynamics (Mutapi et al. 1997), distribution of intermediate hosts (Gryseels et al. 2006), distinct intra-population exposure patterns (Rudge et al. 2008), therapeutic interventions (Mutapi et al. 2005) and concurrent or previous infections with other pathogen species (Correa-Oliveira et al. 2002).

This review highlights differences in the human acquired immune response to a variety of nematode and trematode infections of public health importance and explores some of the factors contributing to these variations, particularly differences arising from helminth life-history traits.

\section{COMMON FEATURES OF THE ACQUIRED}

IMMUNE RESPONSE

The most prevalent human helminthiases are caused by nematode species including filarial worms (Brugia

Parasitology (2011), 138, 139-159. C Cambridge University Press 2010. The online version of this article is published within an Open Access environment subject to the conditions of the Creative Commons Attribution-NonCommercial-ShareAlike licence < http://creative commons.org/licenses/by-nc-sa/2.5/>. The written permission of Cambridge University Press must be obtained for commercial re-use. doi:10.1017/S0031182010001216 


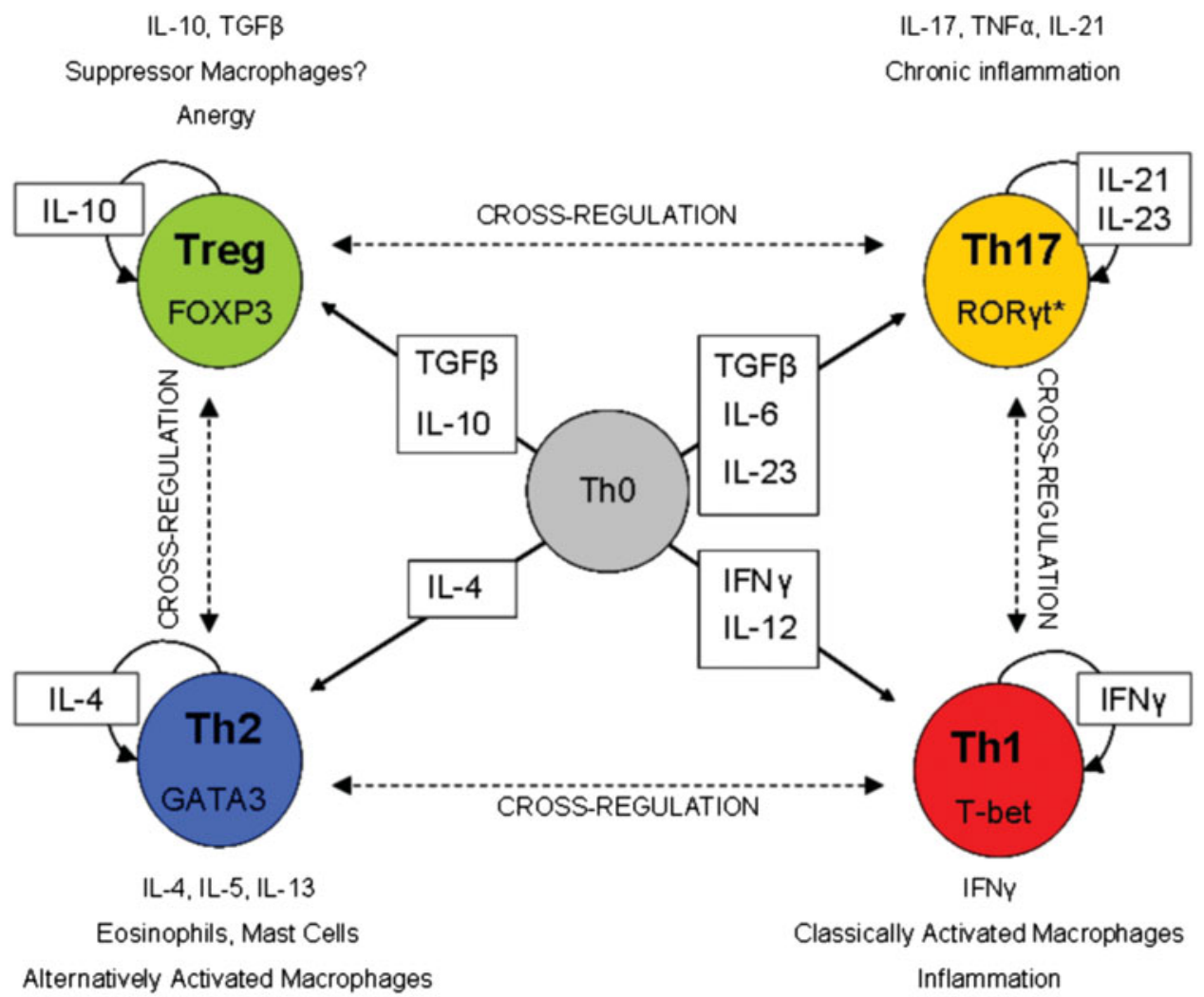

Fig. 1. Summary of the major CD4 $+\mathrm{T}$ cell differentiation pathways following activation in the periphery. Cytokines and transcription factors involved in $\mathrm{T}$ cell polarization are shown in boxes and within cells respectively. Effector cell types and cytokines associated with each CD4 + T cell phenotype are given adjacent to relevant cells. Th0 - naïve T cell, * ROR $\gamma t$-murine transcription factor, the human orthologue is RORC2. Figure adapted from Deenick and Tangyne (2007) and Diaz and Allen (2007).

malayi, Onchocerca volvulus and Wuchereria bancrofti) and soil-transmitted helminths (Hotez et al. 2008): Ascaris lumbricoides, Trichuris trichiura, hookworm (Ancyclostoma duodenale and Necator americanus), Strongyloides spp., and Enterobius vermicularis. Of the trematodes, Schistosoma spp. are of greatest public health importance, with the 3 predominant species (S. haematobium, S. japonicum and S. mansoni) accounting for over 200 million current infections worldwide (Gryseels et al. 2006). In addition, and beyond the scope of this article, there are many important human cestode parasites which have been expertly discussed elsewhere (Zhang et al. 2008).

The principal cellular mediators of humanhelminth interactions are $\mathrm{CD}^{+}{ }^{+} \mathrm{T}$ cells, which can differentiate into alternative lineages once activated; Th1, Th2, Th17 and T regulatory (Treg), as summarized in Fig. 1. Selective differentiation is first driven by innate antigen-presenting cells (APC) but, as responses mature during the course of chronic infection, cytokine-mediated cross-regulation between T cell subsets becomes increasingly important. Differences in acquired immune responses to helminth infection can arise via heterogeneity in how parasites initially interact with host cells, polarize local and systemic responses and/or modulate effector responses in chronic infection. There are two principal immunological features believed to be common amongst helminth infections. (1) Polarization of $\mathrm{CD}^{+}{ }^{+} \mathrm{T}$ cells towards a Th2 phenotype. In humans, this phenotype is associated with production of interleukins (IL-)4, 5, 9, 10 and 13 (Turner et al. 2003; Jackson et al. 2004b; Quinnell et al. 2004), secretion of $\mathrm{IgE}$ and $\mathrm{IgG} 4$ isotypes by plasma cells (Hagan et al. 1991) and activation of downstream effector cells such as eosinophils (reviewed by (Klion and Nutman, 2004)). (2) Immunosuppression of both worm-specific and generalized immune responses. Inducible mechanisms include secretion of suppressive cytokines, such as IL-10 and TGF- $\beta$, and expansion of regulatory cell populations, particularly Tregs (Doetze et al. 2000; Watanabe et al. 2007; Babu et al. 2009). The progression of host responses from effector 'Th2 to a so-called 'modified Th2' phenotype associated with elevated levels of Treg-associated molecules and reduced Th2 effector cytokine responses (Maizels and Yazdanbakhsh, 2003), suggests that both features play a functional, and potentially cross-regulatory, role in helminth immunobiology.

Despite similarities in the immune responses elicited by different helminths, immunological studies often yield contradictory results in different human populations and different species of helminth infection, which are discussed below. To an extent this is 
unsurprising as expanding research into human helminthiases has inevitably led to a greater appreciation of the intricacies of their immunobiology. The discovery of new cell populations including Treg and Th17 and the more recent description of IL-5 and IL-9 producing CD4 + T cells, which differentiate from Th2 cells in an IL-33 or TGF- $\beta$ / IL-4-dependent manner respectively, has led to a re-evaluation of the classical Th1-Th2 paradigm (Dardalhon et al. 2008; Kurowska-Stolarska et al. 2008; Veldhoen et al. 2008). Furthermore the CD4+ $T$ cell axis can be regulated both by effector cytokines from CD $4+\mathrm{T}$ cell populations themselves (IFN $\gamma$, IL-4 and IL-21 (Wilson et al. 2008; Babu et al. 2009)) and innate and adaptive non- $T$ cell populations, which both present antigen to activate $\mathrm{T}$ cells and contribute significant levels of these same cytokines. Helminth-induced alternatively activated macrophages exhibit particular plasticity in this respect (Jenkins and Allen, 2010). Studies showing that Th2 IL-4 and IL-5 responses can be dissociated in human nematode (Sartono et al. 1997) and trematode (Scott et al. 2000) infections indicate that even established immune phenotypes involve heterogeneous effector responses to helminth infection. As more data become available on human anti-helminth responses, particularly in terms of the more recently described cytokines (e.g. IL-17, IL-21, IL-23, IL-33), comparative studies between helminth groups will be better able to identify similarities and differences in these responses.

\section{HETEROGENEITY IN PROTECTIVE IMMUNE} RESPONSES

Protective immunity in human helminthiases encompasses a range of overlapping mechanisms: (a) complete elimination of parasites (sterile immunity), (b) resistance to de novo infection (non-sterile immunity, also called 'concomitant immunity') and (c) reduction of immunopathology (tolerance). The former two processes can be grouped as anti-parasite immunity, whilst the latter involves immune-mediated regulation of pathological effector responses. The high prevalence of chronic helminth infection in endemic populations suggests that sterile immunity is rarely generated (Hotez et al. 2008). However, the decline in infection intensity at an earlier age in populations with high infection intensity (Woolhouse, 1998) and more rapid development of resistance to re-infection post-treatment in individuals with longterm exposure to infection (Black et al. 2010) indicates that non-sterile immunity, though slow to develop, does occur with cumulative exposure. Conversely, since the majority of helminth infections are asymptomatic, it is clear that tolerance of low-level infection can be readily elicited to limit immunopathology (Dessein et al. 2004). The balance between anti-parasite and anti-pathology responses is inevitably shaped by the specific immunopathogenesis of different helminth species. Contrary to phylogenetic distinctions between nematodes and trematodes, one of the main functional delineations between helminth infections is that between species where adult worms reside in the gastrointestinal (GI) tract and those that inhabit host tissues.

\section{Anti-parasite immune responses}

Expulsion of GI nematodes is dependent on highly polarised Th2 responses (reviewed by (Jackson et al. 2009; Jenkins and Allen, 2010)) and elevated titres of systemic and parasite-specific Th2 cytokines are negatively associated with infection intensity in untreated populations (Turner et al. 2003). Th2-induced smooth muscle hypercontractility and mucus secretion by goblet cells are known to facilitate clearance of murine GI nematode infections (Finkelman et al. 2004), but these physical means of worm expulsion are absent in the tissues. The immunological relevance of these differences has not been tested in humans.

Resistance to re-infection by GI nematodes post-treatment also tends to be unequivocally Th2mediated (Jackson et al. 2004a,b; Quinnell et al. 2004). Post-treatment resistance to hookworm and T. trichiura infection is associated with pre-treatment levels of IL-5 (Jackson et al. 2004a; Quinnell et al. 2004) and negative associations have also been shown between IL-5/IL-13 and re-infection with A. lumbricoides and T. trichiura (Jackson et al. 2004b). However, even between GI nematode species the relationship between Th2 cytokines and resistance to re-infection has been shown to vary according to parasite life-history. For example despite multiple shared risk factors for co-infection with A. lumbricoides and $T$. trichiura, pre-treatment Th2 cytokine titres were only associated with post-treatment resistance to the latter (Jackson et al. 2004a). Furthermore, parasite-specific IL-10 was found to be an indicator of species-specific susceptibility, being negatively associated with $T$. trichiura but positively associated with $A$. lumbricoides egg counts (Jackson et al. 2004a).

Th2-type responses are also involved in protective immunity in tissue-dwelling helminths; however, chronically infected individuals tend to mount Th1-Th2 mixed responses (Joseph et al. 2004; Mutapi et al. 2007), thought to be involved in limiting infection intensity (Turaga et al. 2000). In an O. volvulus-endemic population in Cameroon, despite a predominant Th2 bias, putative immunity correlated with elevated titres of parasite-specific Th1 (IFN $\gamma$ ), Th2 (IL-5) and innate (granulocytemacrophage colony-stimulating factor (GM-CSF)) effector cytokines (Turaga et al. 2000). Similarly, schistosome-specific IFN $\gamma$ production by peripheral 
blood mononuclear cells (PBMC) correlates with immunity to schistosomiasis (Viana et al. 1994). Mixed Th1-Th2 cytokine responses are observed in chronic trichuriasis in the gut but have not been significantly associated with infection intensity (Faulkner et al. 2002).

Antibody-mediated protection from helminths is typically attributed to elevated titres of parasitespecific IgE (Faulkner et al. 2002; Pearce and MacDonald, 2002), whilst a low IgE:IgG4 is associated with susceptibility to schistosome (Hagan et al. 1991) and GI infections (Figueiredo et al. 2010). However, positive correlations between parasitespecific IgE and other isotypes (Viana et al. 1995) and studies identifying more pronounced associations between infection intensity and non- $\mathrm{IgE}$ isotypes (Webster et al. 1997) suggest that there is redundancy in antibody-mediated protective immunity. In addition, given the potentially immunopathogenic outcomes of IgE-mediated cellular effector responses (Nutman and Kumaraswami, 2001; Cooper et al. 2004), it is unsurprising that propagation of alternate antibody isotypes in chronically infected hosts may be favourable. A variety of studies investigating other antibody isotypes in schistosomiasis provide conflicting evidence for their role in resistance to infection with different species. For example, whilst polyclonal adult worm-specific IgA titres decline with age and infection intensity in S. haematobium endemic areas (Mutapi et al. 1997), the opposite pattern has been observed for S. japonicum-specific IgA in the Philippines (Acosta et al. 2004). Similarly, whilst the former study found that $S$. haematobium adult worm-specific IgG1 increased with age and peaked in individuals with low infection intensity (Mutapi et al. 1997), IgG1 titres were significantly positively associated with intensity of S. mansoni infection in Brazil (de Jesus et al. 2000) and Kenya (Naus et al. 1999). The role of $\mathrm{IgM}$ in anti-schistosome responses is also controversial as adult worm and egg-specific IgM increase with S. haematobium and S. japonicum infection intensity in some populations (Mutapi et al.1997; Acosta et al. 2004), but adult-worm-specific titres were lowest in individuals patently infected with $S$. mansoni elsewhere (Viana et al. 1995; Caldas et al. 2000). Potential sources of variation in protective immunity within and between schistosome-infected populations are discussed in the following sections.

For filarial infections larvae-specific antibodies acquired with age have been shown to confer resistance to re-infection post-treatment (Day et al. 1991b); however, the immunogenic epitopes within the larval proteome could not be identified (Day et al. 1991a). Few studies have directly compared schistosome and nematode-specific antibody responses; however, studies to date suggest that differences do exist. $W$. bancrofti microfilaria and circulating antigen negative individuals were found to have the lowest parasite-specific IgG4:IgE (Jaoko et al. 2006) as has been observed in schistosome studies (Hagan et al. 1991). However, unlike in chronic schistosomiasis, the ratios did not differ between communities with high and low intensity infection indicating that relative changes in these isotypes may be less dependent on host exposure history (Jaoko et al. 2006). IgG2 also appears to limit infection intensity when directed against $W$. bancrofti microfilaria (Jaoko et al. 2006), but is ineffective against schistosome larvae (Demeure et al. 1993).

The specific target of antibody responses is particularly important for development of protective immunity, although the majority of field studies focus on crude antigen preparations. Early schistosome studies identified isotype-specific antibody responses to different antigen types within the parasite proteome (Langley et al. 1994), but it was not until the advent of mass spectrometric analysis that parasite peptides recognized by different antibody isotypes could be identified within crude preparations (Mutapi et al. 2005, 2008). Relative exposure of immunogenic peptides clearly plays a role in cumulative development of protective antibodies. For example, antibodies against the larval surface are associated with protection against $W$. bancrofti (Day et al. 1991a) and antibodies targeting cryptic antigens released by dying adult worms may influence the course of schistosome infection (Woolhouse and Hagan, 1999). It remains unclear whether there is a single antibody isotype that uniformly protects against helminth infection and it seems likely that redundancy within host antibody responses, variation between parasite species and/or host populations have all contributed to isotype-specific variations observed in the field.

\section{Anti-pathology immune responses}

Limiting immunopathology in patent helminth infection is a combination of parasite and host-mediated processes that synergize to limit aberrant immune reactivity and damage to the host. This is necessarily a compromise as dampening immune responses to infection also limits their efficacy at clearing infection (Maizels and Yazdanbakhsh, 2003). For tissuedwelling helminths close association with host tissues throughout their life-cycle means that effector responses to adult worms and migrating larvae in these loci must be tightly regulated (Montenegro et al. 1999). In chronic schistosomiasis, for example, Th2-polarized responses account for the majority of host pathologies including hepatic fibrosis (Coutinho et al.2007) and egg-specific responses promote granuloma formation (ElRidi et al. 1997), whilst Th2mediated damage is mitigated by Th1-type (Henri et al. 2002; Dessein et al. 2004) and innate inflammatory cytokines (TNF $\alpha$ and IL-6 (Booth et al. 
2004a; Wilson et al. 2008)). The importance of Tregs in balancing Th1 and Th17 responses in human filarial infections has been recently highlighted by Babu and colleagues who identified a positive correlation between lymphoedema and Th1/Th17 cytokine and Toll-like receptor expression in individuals with low expression of Treg-associated molecules (Babu et al. 2009).

Ubiquitous exposure to commensal bacteria and food antigens means that antigen-presentation and inflammatory responses are highly regulated in the gut to maintain a physical barrier between the lumen and host tissues (Mayer, 2000). GI nematodes are also able to actively down-regulate effector responses in the gut to maintain this regulatory environment (reviewed by Maizels and Yazdanbakhsh, 2003). Both Ascaris spp. and Trichuris spp. infections are also associated with reduced cellular responsiveness to both non-specific agonists and parasite-specific antigens in humans (Figueiredo et al. 2010). The rebound in $N$. americanus-specific IFN $\gamma$ observed after anti-helminthic treatment to clear infection suggests that Th1 responses may be particularly regulated in chronic hookworm infection (Quinnell et al. 2004).

However, GI nematodes are not homogeneous in the immune responses that they induce and thus pose distinct immunopathological risks. T. trichiura infection induces a mixed Th1-Th2 cytokine profile (Faulkner et al. 2002), whilst Ascaris lumbricoides infection leads to a highly Th2 environment (Cooper et al. 2000). It has been postulated that murine Trichuris spp. are distinct from other GI infections in specifically up-regulating Th1 cytokines as a means of evading Th2-mediated clearance (refer to review by Else, 2005); however, fostering a more mixed cytokine response may also limit pathology. IL-10 secretion is highly prevalent in T. trichiura endemic populations with $97 \%$ of a Cameroonian cohort secreting parasite-specific IL-10 and older individuals producing the highest titres of non-specific IL-10 (Faulkner et al. 2002), suggesting that systemic immunoregulation coincides with cumulative exposure to infection.

SOURCES OF ACQUIRED IMMUNE

HETEROGENEITY

\section{Helminth life history}

Helminths undergo complex life cycles leading to both physical and molecular variations during the course of an infection. Table 1 summarizes the key differences in helminth life histories that can introduce heterogeneity in the development of the host immune response to infection. Furthermore, the range of molecules and mechanisms that underlie helminth-mediated immunomodulation have been reviewed elsewhere (Maizels and Yazdanbakhsh,
2003; Maizels et al. 2009) and present a potential source of immune heterogeneity in themselves.

\section{Parasite transmission route}

Transmission route impacts upon where and how infection is initially detected by the immune system. Immature helminths face site-specific challenges as they invade their host, for example species that are transmitted through the skin tend to suffer immune attrition in this organ (He et al. 2005). Amongst the schistosome species, which invade by active penetration, $S$. japonicum cercariae migrate most rapidly to the dermis and this species also elicits the most pro-inflammatory response in human skin (He et al. 2002). In contrast S. haematobium and S. mansoni cercariae promote up-regulation of immunoregulatory proteins including IL-10 and IL-1 receptor antagonist (He et al. 2002), highlighting heterogeneity in the effector and regulatory immune mechanisms elicited even by closely-related species.

Arthropod-borne larvae are also exposed to immune attrition in human cutaneous tissue when they enter during blood-feeding by the vector. However, unlike actively penetrating parasites, antigens, enzymes and immunosuppressive molecules in arthropod saliva may skew the host immune response in favour of vector-transmitted larvae (Demeure et al. 2005). Furthermore, where a single helminth species (such as $W$. bancrofti) can be transmitted by multiple mosquito species of 4 different genera (Aedes, Anopheles, Culex and Mansonia) (Maizels and Kurniawan-Atmadja, 2002), there is potential for the human immune response to be differently shaped in each instance. The presence of Wolbachia spp. bacterial endosymbionts in mosquito vectors and almost all filarial helminth species has also been suggested to influence host $\mathrm{T}$-cell responsiveness (Brattig, 2004), but this is yet to be verified.

On a broader scale transmission route can determine distribution of immune-mediated morbidities within host populations. One example is the lower prevalence of Sowda in O. volvulus-infected men relative to women inhabiting the same area, which has been attributed to development of immune tolerance after repeated exposure to $O$. volvulus vectors during agricultural work (Brattig, 2004; Trpis, 2006).

Following initial infection, larval migration may also contribute to immune heterogeneity between GI nematodes, particularly with respect to antipathology immunity. Clinical measures of atopic reactivity suggest that hookworm with lung-migratory stages effectively suppress asthma and wheeze in the lung (Scrivener et al. 2001; Leonardi-Bee et al. 2006). Therapeutic N. americanus infection is able to dampen inflammation both in the lung and in the gut, where adult worms reside (Falcone and Pritchard, 2005; Croese et al. 2006). On the other hand, Trichuris spp. which inhabit the lower intestine and 
Table 1. Summary of parasite-factors that may influence the host acquired immune response to helminth infection (Anderson and May, 1992; Maizels et al. 1993; Maizels and Kurniawan-Atmadja, 2002; Gryseels et al. 2006; Hotez et al. 2008).

\begin{tabular}{|c|c|c|c|c|c|c|c|c|c|c|c|}
\hline & \multicolumn{4}{|c|}{ Gastrointestinal (GI) nematodes } & \multicolumn{4}{|c|}{ Filarial nematodes } & \multicolumn{3}{|c|}{ Schostosoma spp. trematodes } \\
\hline & A. lum & E.ver & N. ame & Stro. spp. & T. tri & B. mal & O. vol & $W$. ban & S. hae & S. jap & S. man \\
\hline Distribution & $\begin{array}{l}\text { Af, As, } \\
\text { LAm }\end{array}$ & - & $\begin{array}{l}\text { Af, As, } \\
\text { LAm }\end{array}$ & $\begin{array}{l}\text { Af, As, } \\
\text { LAm }\end{array}$ & $\begin{array}{l}\text { Af, As, } \\
\text { LAm }\end{array}$ & SEAs & $\begin{array}{l}\text { SSAf, } \\
\text { LAm }\end{array}$ & $\begin{array}{l}\text { As, SSAf, } \\
\text { LAm }\end{array}$ & SSAf & $\begin{array}{l}\text { China, } \\
\text { SEAs }\end{array}$ & $\begin{array}{l}\text { SSAf, } \\
\text { Brazil }\end{array}$ \\
\hline $\begin{array}{l}\text { Human } \\
\text { infections } \\
\text { (millions) }\end{array}$ & 807 & - & $576^{*}$ & $30-100 * *$ & 604 & - & 37 & 120 & $207 * * *$ & $207 * * *$ & $207 * * *$ \\
\hline $\begin{array}{l}\text { Intermediate } \\
\text { host }\end{array}$ & None & None & None & None & None & Ano spp. & Sim spp. & $\begin{array}{l}\text { Ano, Cul } \\
\text { Aed spp. }\end{array}$ & $B u l$ spp. & Onc spp. & B. gla \\
\hline $\begin{array}{l}\text { Transmission } \\
\text { route }\end{array}$ & Faeco-oral & Faeco-oral & $\begin{array}{c}\text { Skin } \\
\text { penetration }\end{array}$ & $\begin{array}{c}\text { Skin } \\
\text { penetration }\end{array}$ & Faeco-oral & Vector & Vector & Vector & $\begin{array}{c}\text { Skin } \\
\text { penetration }\end{array}$ & $\begin{array}{c}\text { Skin } \\
\text { penetration }\end{array}$ & $\begin{array}{c}\text { Skin } \\
\text { penetration }\end{array}$ \\
\hline $\begin{array}{l}\text { Maturation } \\
\text { delay }\end{array}$ & $50-80$ days & $15-43$ days & $40-50$ days & - & $50-84$ days & - & 365 days & - & $21-28$ days & $25-30$ days & $25-30$ days \\
\hline $\begin{array}{l}\text { Adult worm } \\
\text { life-span }\end{array}$ & $1-2$ years & $<1$ year & $2-3$ years & - & $1-2$ years & - & $8-10$ years & $3-5$ years & $3-5$ years & $3-5$ years & $6-11$ years $^{\wedge}$ \\
\hline $\begin{array}{l}\text { Adult worm } \\
\text { length }\end{array}$ & $15-35 \mathrm{~cm}$ & $2-13 \mathrm{~mm}$ & $7-11 \mathrm{~mm}$ & - & $\sim 4 \mathrm{~cm}$ & $13-55 \mathrm{~mm}$ & $19-50 \mathrm{~mm}$ & $40-100 \mathrm{~mm}$ & $7-20 \mathrm{~mm}$ & $7-20 \mathrm{~mm}$ & $7-20 \mathrm{~mm}$ \\
\hline $\begin{array}{l}\text { Adult worm } \\
\text { niche }\end{array}$ & Ileum & Caecum & Ileum & Caecum & Caecum & Lymph & Skin & Lymph & $\begin{array}{l}\text { Venous blood } \\
\text { (bladder) }\end{array}$ & $\begin{array}{c}\text { Venous } \\
\text { blood (gut) }\end{array}$ & $\begin{array}{c}\text { Venous } \\
\text { blood (gut) }\end{array}$ \\
\hline $\begin{array}{l}\text { Fecundity per } \\
\text { female }\end{array}$ & $\begin{array}{l}200,000 \\
\text { eggs/day }\end{array}$ & - & $\begin{array}{c}\text { 3000-6000 } \\
\text { eggs/day }\end{array}$ & - & $\begin{array}{c}50-84 \\
\text { eggs/day }\end{array}$ & - & $\begin{array}{c}1000-2000 \\
\mathrm{mf} / \text { day }\end{array}$ & - & 3000 eggs/day & $\begin{array}{l}\text { 100-300 } \\
\text { eggs/day }\end{array}$ & $\begin{array}{l}\text { 100-300 } \\
\text { eggs/day }\end{array}$ \\
\hline
\end{tabular}

* All hookworm species.

** Strongyloides stercoralis only.

*** All $S$. haematobium, $S$, japonicum and $S$. mansoni infections.

$\wedge$ Life-span of S. mansoni estimated using maximum likelihood techniques to assess pre- and post-treatment field data (Fulford et al. 1995).

Abbreviations: A. lum-Ascaris lumbricoides, E. ver-Enterobis vermicularis, N. ame-Necator americanus, Stro spp. -Strongyloides spp., T. tri-Trichuris trichiura, B. mal-Brugia malayi, O. vol-Onchocerca volvulus, W. ban-Wuchereria bancrofti, S. hae-Schistosoma haematobium, S. jap-Schistosoma japonicum, S. man-Schistosoma mansoni, Af-Africa, As-Asia, LAm-Latin America, SEAs-South East Asia, SSAf-Sub-Saharan Africa, Ano spp.-Anopheles spp. mosquito, Aed spp.-Aedes spp. mosquito, Cul spp.-Culex spp. mosquito, B. gla-Biomphalaria glabrata (aquatic snail), Bul spp.-Bulinus spp. (aquatic snail), mf-microfilariae. 
do not migrate through the lung, can dampen inflammatory pathologies in the gut (Reddy and Fried, 2007) but are less effective at regulating clinical allergy elsewhere (Bager et al. 2010). Interestingly A. lumbricoides infection, which has a lung migratory phase, does not reduce asthmatic responses and is associated with elevated atopy (Flohr et al. 2009). There are many potential reasons for variation in the effect of GI helminth infection on clinical allergy (reviewed elsewhere (Flohr et al. 2009)) and conflicting results in existing literature (Leonardi-Bee et al. 2006) and a lack of studies which directly compare GI nematode infections with distinct migratory pathways make it difficult to conclude on the source of observed variations.

\section{Life-cycle stages}

Chronically infected individuals are simultaneously exposed to 3 helminth life-cycle stages; infective larvae, adult worms and transmission stage parasites (eggs, immature larvae or microfilariae). Both proteomic (Moreno and Geary, 2008) and DNA microarray studies (Jolly et al. 2007; Fitzpatrick et al. 2009) have shown that these life-cycle stages are molecularly different and thus elicit stage-specific immune responses that change over time.

In experimental murine studies where the course of infection can be tracked from its acute phase, there is a clear link between the onset of egg production (week 5-6 post-infection) and a Th1-to-Th2 shift in the cellular response to schistosomiasis (Pearce and MacDonald, 2002). Although the Th1-to-Th2 shift is less clear in human infections, defined egg peptides can specifically induce Th2 responses in human basophils, DCs and T cells in vitro (Schramm et al. 2003; Everts et al. 2009). Th2 polarization by schistosome eggs also induces granuloma formation (ElRidi et al. 1997), which facilitates passage of eggs from venous blood into the gut/bladder and subsequent transmission to the environment (Karanja et al. 1997; Pearce and MacDonald, 2002). Carbohydrate antigens on the schistosome egg surface also promote IgM secretion, which lacks immunological memory (Mutapi et al. 2003), whilst responses associated with protective immunity, such as $\mathrm{IgE}, \mathrm{IgG} 1$ and $\mathrm{IgG} 3$, tend to emerge later in infection in response antigens released from dying adult worms (Woolhouse and Hagan, 1999).

There are notable distinctions between the type and magnitude of the cytokine response to eggspecific antigens and those directed against adult worm antigens (Joseph et al. 2004; Silveira et al. 2004). Adult S. mansoni worms tend to elicit a mixed Th1-Th2 cytokine profile (Williams et al. 1994) and are less effective at stimulating in vitro granuloma formation (IVGF) than egg antigens (ElRidi et al. 1997). Cross-sectional data from an S. haematobium endemic cohort suggests that adult worm-specific effector Th2 cytokines increase whilst IL-10 titres decline with age/exposure to infection (Mutapi et al. 2007) and thus effector responses to adult worms are higher in putatively resistant individuals.

In contrast to the Th2 cytokine responses induced by schistosome eggs and infective larvae of most nematodes, schistosome cercariae stimulate Th1/ inflammatory mRNA expression in mice and resistance to larval invasion post-vaccination is dependent on IFN $\gamma$ (Wynn et al. 1994). Although few studies have directly compared immune responses to the three schistosome life-cycle stages in humans, cercariae-specific IgM, IgG1 and IgG4 titres are higher than those directed against adult worm antigens (Viana et al. 1995). The distinct immune responses elicited by different helminth life-cycle stages underpin the development of so-called concomitant immunity, whereby de novo larval infection is blocked by adult worm-induced immunity but resident adult parasites are tolerated, a theory originally formulated for schistosome infections (Smithers and Terry, 1967). Studies have found evidence for development of PBMC-mediated resistance to L3 invasion in $O$. volvulus infection in an endemic area of Cameroon (MacDonald et al. 2002) and development of peripheral antibody-dependent immunity to $W$. bancrofti larvae with age in Papua New Guinea (Day et al. 1991a,b). There is little evidence for development of concomitant immunity to GI nematode infections; however, there is a distinct paucity of data in this area.

In addition to influencing anti-parasite immunity, helminth life-cycle stage contributes to heterogeneity in anti-pathology immune responses. Immunomodulatory processes can be life cycle stage-specific as characterized by distinct cytokine and proliferative responses to their respective antigens (Geiger et al. 2007). In vitro microfilariae are able to impair cytokine expression and maturation of human dendritic cells (DCs) (Semnani et al. 2001, 2004) and schistosome egg antigens can inhibit co-stimulatory molecule expression and skew APC cytokine secretion from an inflammatory to regulatory profile (Correale and Farez, 2009), with potential implications for the systemic CD4 + T cell phenotype. A variety of studies have also shown that cercariae excretory/ secretory products actively modulate the host immune response during migration and maturation independent of egg or adult-worm-mediated processes (reviewed by Jenkins et al. 2005). However, whilst eggs, cercariae and microfilariae can impair and polarize host responses, the ability of parasites to evade and modulate immune recognition seems to increase as they mature (Nutman and Kumaraswami, 2001) and corresponds to large-scale switches in many suites of genes (Jolly et al. 2007) and active secretion of immunomodulatory molecules (Geiger et al. 2007). Thus, despite being exposed to the host 

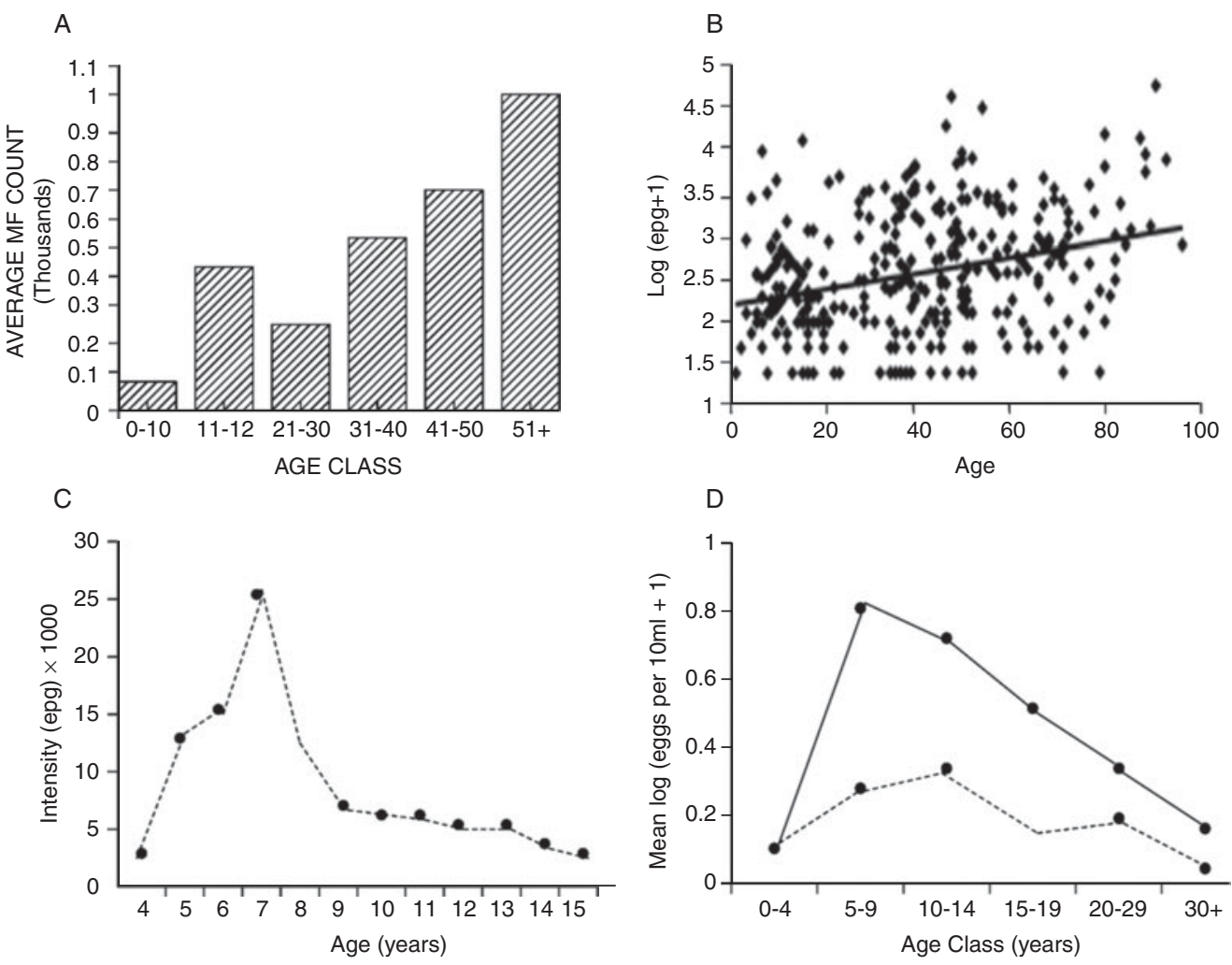

Fig. 2. The relationship between age and infection intensity in natural human helminthiases. (A) Mean $W$. bancrofti microfilaria (mf) count by age group ( $n=156$, study area: Papua New Guinea, method: microscopy of $2 \mathrm{ml}$

Giemsa-stained blood). Reprinted from the American Fournal of Tropical Medicine and Hygiene (Day et al. 1991b), with permission from the managing editor. (B) Mean hookworm (A. duodenale and $N$. americanus) egg counts per gram faeces (EPG) by age group ( $n=631$, study area: China, method: Kato-Katz thick smear). Reprinted from the Fournal of Parasitology (Gandhi et al. 2001), with permission from Allen Press Publishing Services. (C) Mean T. trichiuris eggs per gram of faeces by age group ( $n=96$, study area: Cameroon, method: Kato-Katz thick smear). Reprinted from the Fournal of Infectious Diseases (Faulkner et al. 2002), with permission from the University of Chicago Press.

(D) Age-infection intensity profiles of S. haematobium egg counts per $10 \mathrm{ml}$ of urine from an area of low infection prevalence (dashed line) and an area of high infection prevalence (solid line) group $(n=133$ and 147, study area: Zimbabwe, method: filtration of $10 \mathrm{ml}$ of urine) (re-drawn from Mutapi et al. 1997). Reprinted from Parasitology Today (Woolhouse, 1998), with permission from Elsevier and John Wiley and Sons Ltd.

immune system for the longest of all life-cycle stages, it is unsurprising that adult worms are so resistant to immune-mediated clearance (Maizels and Yazdanbakhsh, 2003), while immature parasites tend to be immunogenic, more readily killed by effector immune responses (Viana et al.1995; Semnani et al. 2001; Medeiros et al. 2003) and are responsible for the majority of morbidity in helminth infections (Maizels and Yazdanbakhsh, 2003).

\section{Parasite life-span}

Unlike microbial infections which multiply exponentially in their hosts, helminths have evolved to invest in immune-evasive mechanisms to prolong intra-host survival and long-term fecundity (Jackson et al. 2009). Effective immune evasion and suppression by adult worms mean that reactivity to the antigens of live worms is limited (Geiger et al. 2007). Thus, hosts may only experience an immunogenic 'threshold' stimulus of parasite antigens once adult worms die (Mutapi et al. 2008) and resistance might be predicted to develop more slowly against longlived worms than against shorter-lived species. The rapid switch to a protective immune profile following anti-helminthic drug treatment that kills adult worms is consistent with this hypothesis (Mutapi et al. 2003; Watanabe et al. 2007). If adult helminth life-span does cause a lag in the development of protective immunity then this may contribute to the variation in the age at which peak prevalence (Brooker et al. 2000) and infection intensity (Fig. 2) occurs in host populations exposed to different helminths.

Additionally, whilst some helminths have been known to survive for extremely long periods (Vermund et al. 1983), most die before reaching their maximum longevity. It is possible that the relatively short average helminth life-span in immunocompetent individuals reaps the maximal reproductive success relative to the physiological cost to the parasite of evading and modulating the host 
immune response. In opposition to this, studies in hookworm suggest that the immune response has only a limited impact on parasite longevity (reviewed by Loukas and Prociv, 2001). Species with indirect life cycles, such as Schistosoma spp. and vector-borne helminths, tend to be long-lived (Table 1). Thus, once adult worms have adapted to their optimal host niche, they can produce offspring over a long period and, whilst they are immunogenic, adult worms do not appear to be the primary targets of the antihelminth immune response in humans or in animal models (Smithers and Terry, 1967). This may be particularly true of $O$. volvulus, which has an average adult life-span of 8-10 years, but can have a maturation delay in the human host of over a year (Anderson and May, 1985). For short-lived worms, such as E. vermicularis, maturation and oviposition occurs much earlier, with an associated shift in stagespecific immune responses (Anderson and May, 1985).

\section{GENETIC HETEROGENEITIES IN HELMINTH} I N F ECTION

\section{Host genetics}

The human immune system has evolved in the context of helminth infection and this relationship has led to significant changes in our immune genes (Fumagalli et al. 2009; Maizels, 2009). A recent comprehensive study of 91 interleukin genes in 52 human populations found evidence for balancing selection in the evolution of the human immune response driven by helminth 'species richness', i.e. the greater diversity of helminths to which a population has been exposed, the greater diversity observed in interleukin alleles (Fumagalli et al. 2009). These findings are consistent with helminths differentially affecting the human acquired immune response at all levels of the CD4+ $\mathrm{T}$ cell axis, including gene families involved in inflammation in the skin, mucosal immunity, cell proliferation and survival and Th2 cytokines (Fumagalli et al. 2009). This is compounded by earlier studies indicating that many of the key genetic loci controlling the balance of effector and regulatory responses are polymorphic in the human population (Quinnell, 2003) and that certain human genes are associated with predisposition to infection with specific helminth parasites (Hoerauf et al. 2002; Peisong et al. 2004; Kouriba et al. 2005).

Additive genetic effects (heritability) significantly influence human infections with $A$. lumbricoides (Williams-Blangero et al. 2002b), T. trichiura (Williams-Blangero et al. 2002a), and S. mansoni (Bethony et al. 2002), whilst other studies have found host genetics to be less influential relative to exposure history (King et al. 2004). This conflicting evidence suggests that helminth distribution, allele frequency and host behaviour in each locality may determine the relative importance of heritable factors in patterns of infection and immunity (Ellis et al. 2007). Familial clustering of infection can further confound identification of genetic factors associated with helminth infection since in utero sensitization via transfer of helminth antigens and soluble immune factors from infected mothers to their offspring is independent of genotype (Eloi-Santos et al. 1989; Lammie et al. 1991; Novato-Silva et al. 1992) and co-habiting families often have similar exposure patterns (Smith et al. 2001). T. trichiura and A. lumbricoides for example were found to be significantly associated with shared living conditions; however, when infection distribution was investigated in more depth, only T. trichiura infection intensity was heritable (Ellis et al. 2007). In addition, populations in historically stable endemic areas may exhibit less heritable variation in host susceptibility if long-term selection against genotypes less favourable for a specific infection has occurred (King et al. 2004), particularly where other species of helminth infection are uncommon (Fumagalli et al. 2009).

Multiple gene loci have now been implicated in determining the degree of resistance to helminthiases and while many appear to relate to individual helminth species (reviewed by Quinnell, 2003), there are also loci controlling multiple susceptibilities, as is the case for IL-13 polymorphisms associated with predisposition to $S$. haematobium (Kouriba et al. 2005) and O. volvulus (Hoerauf et al. 2002).

\section{Parasite genetics}

Widespread genetic variation between parasite species is an equally important source of heterogeneity in the development of acquired immune responses to infection. Since parasitic nematodes have arisen from several independent evolutionary pathways their classification within the Phylum Nematoda belies the huge diversity apparent from their distinct life-histories, physiology and proteomes (Dorris et al. 1999). Comparisons between nematode worms at the genomic level have identified multiple speciesspecific gene sequences and transcription patterns, even between phylogenetically close organisms (Parkinson et al. 2004). Among the 3 major human Schistosoma spp. differences in immunologically relevant antigens have been found. Notably the leading anti-schistosome vaccine candidate antigen; glutathione-S-transferase (GST), of S. mansoni differs from that of S. haematobium (Trottein et al. 1992), though the impact of this on human immunity is unknown.

The existence of helminth homologues of human proteins (Pastrana et al. 1998; Gomez-Escobar et al. 2000) and analyses that indicate more rapid evolution among parasite secreted proteins are compatible with the idea that parasitic helminths are diversifying 
fastest among antigens exposed to (and interacting with) the host immune system (Hoekstra et al. 2000; Harcus et al. 2004). The relatively recent completion of the first parasitic nematode (B. malayi; Ghedin et al. 2007) and trematode genome projects (S. mansoni; Berriman et al. 2009) and S. japonicum (Zhou et al. 2009) will inevitably yield greater insights into the evolution of genetic diversity between different helminth species.

Genetic diversity within helminth species may partly explain the slow development of protective immunity in endemic populations. It has been proposed that natural infections consist of several genetically distinct parasite strains (Galvani, 2005), evidence for which comes from variations in the noncoding sequence identified via genome-wide scans (Hunt et al. 2008; Redman et al. 2008). The effect of helminth strains on the host immune response has been investigated in theoretical models based on field studies of $A$. lumbricoides, $N$. americanus, $S$. haematobium and $T$. trichiura infections, which surmise that challenge with multiple strains delays development of resistance to infection in human populations because a different protective response must be mounted against each parasite genotype separately (Galvani, 2005).

\section{INDIVIDUAL EXPOSURE HISTORY}

The immune environment to which de novo helminth infections are exposed is not independent of a host's infection history (Woolhouse and Hagan, 1999). This was first demonstrated in a study of Sudanese canal workers hyper-exposed to S.mansoni infection, which showed that those who had been occupationally exposed for over 10 years were more resistant to infection than newly recruited workers (Satti et al. 1996). More recently a direct comparison between 2 occupationally exposed male cohorts, found that chronically exposed individuals develop resistance to $S$. mansoni re-infection after significantly fewer rounds of praziquantel treatment than those with a shorter exposure history (Black et al. 2010).

It is well known that in endemic populations worm burdens accumulate with age to a peak intensity and decline thereafter (Fisher, 1934) but the age at which peak prevalence occurs (Brooker et al. 2000) and the relative decline post-peak varies according to helminth species (Fig. 2). For example, intensity of $W$. bancrofti (Fig. 2A) and hookworm (Fig. 2B) infections tends to be highest in adults rather than children (Day et al. 1991b; Gandhi et al. 2001). In contrast, T. trichiuria (Fig. 2C) and schistosome (Fig. 2D) infection intensity peaks in childhood, after which worm burdens decline (Mutapi et al. 1997; Faulkner et al. 2002). Host behaviour may partially explain these differences, for example the risk of hookworm infection is highest in adults due to occupation-related exposure (Bradley and Chandiwana,
1990), whilst exposure to schistosomiasis is determined by contact with water from an early age during washing and domestic activities (Rudge et al. 2008).

Evidence that the host immune response is important in shaping age-related variation includes the observation that peak worm burdens occur at a younger age in regions of high infection intensity than in regions with low or intermediate intensity, a phenomenon called the 'peak shift' (Woolhouse, 1998) (Fig. 2D). It is clear that, at least for longterm residents of an area endemic for a particular species of helminth, age is effectively a proxy of exposure history and cumulative exposure to parasite antigens over time can trigger changes in the immune response (Mutapi et al. 2008). The latter assertion is supported by immuno-epidemiological studies in a variety of helminthiases indicating that cellular and humoral changes correlate with development of resistance to infection with age. For example in an S. haematobium-infected population, cross-sectional data showed that cytokine responses switch from a regulatory IL-10 response in younger individuals to an effector IL-5 response in older individuals (Mutapi et al. 2007). Longitudinal studies of $W$. bancrofti-infected subjects in Papua New Guinea showed that adults are relatively resistant to parasite accrual (Day et al. 1991b) and that this could be attributed to parallel age-specific acquisition of anti-larval antibodies (Day et al.1991a). As discussed above, development of this form of concomitant immunity may be one explanation for the lower prevalence of these species in adults (Day et al. 1991 a,b; MacDonald et al. 2002).

In areas of high intensity transmission, people are exposed to infection from a very early age and these patterns vary according to parasite species (SousaFigueiredo et al. 2008). A recent study in Zanzibar found that whilst schistosome infections were rare in pre-school children, soil-transmitted helminths were already highly prevalent (Sousa-Figueiredo et al. 2008). Variation in maternal infection status may also introduce variation in the in utero exposure patterns and potentially lead to long-lasting effects on the antihelminth immune response of their offspring. For example, Steel and colleagues showed that prenatal priming during maternal helminth infection has far-reaching effects on anti-filarial immunity including clonal deletion of parasite-specific $\mathrm{T}$ cells (Steel et al. 1994) and life-long susceptibility to infection (Steel and Nutman, 2003). Cellular studies in endemic populations have shown that umbilical cord blood lymphocytes (CBL) from neonates born of $W$. bancrofti-infected mothers mount parasitespecific cytokine responses similar to those of maternal PBMCs and in contrast to neonates born of un-infected mothers (Malhotra et al. 1997). An extension of this study found that schistosome and $B$. malayi-specific cytokine responses persisted in childhood and significantly affected the CD4 + T cell 
polarization of Bacillus Calmette-Guerin (BCG) vaccine-specific responses in 2 to 10 year olds (Malhotra et al. 1999). However, an investigation of CBL responses to $N$. americanus and $O$. volvulus antigens found no evidence for specific polarization of Th1 and Th2 responses in the offspring of helminth-infected mothers (Pit et al. 2000). To date only a very few studies have directly compared the effect of different helminth species on neonatal immunity, though researchers hypothesize that tissue-dwelling helminths may be associated with a greater trans-placental transfer of antigens (EloiSantos et al. 1989; Novato-Silva et al.1992; Malhotra et al. 1997). Since maternal exposure patterns will inevitably affect neonatal and early post-natal exposure the contribution of parasite transmission route and the associated behavioural risk factors for infection to immune heterogeneity (discussed above) should not be overlooked in early life.

\section{ANTI-HELMINTHIC TREATMENT}

Anti-helminthic treatment can effectively clear infection and thus artificially disrupts host-parasite immunoepidemiology, for example immune reactivity has been shown to peak shortly after treatment in many species of helminth infection (Quinnell et al. 2004; Watanabe et al. 2007). Following treatment, however, endemic populations become re-infected and the highest re-infection rates are consistently seen in individuals who carried high worm burdens before treatment suggesting pre-disposition to infection in certain hosts (Bundy et al. 1988; Tingley et al . 1988; Chandiwana et al. 1991).

In addition to clearing infection, even a single dose of chemotherapy can lead to changes in the host immune response to helminths. Successful treatment has been shown to enhance the proportion of effector T cells (Watanabe et al. 2007), increase the range of parasite proteins recognized by host antibodies and induce a more rapid switch to protective antibody isotypes (Mutapi et al. 2003) in schistosomiasis patients. This post-treatment rebound in immune responsiveness could be due to heightened DC activation in an environment of high parasite death (Watanabe et al. 2007) and/or recovery of normal immune function following removal of immunosuppressive parasite excretory/secretory products (Maizels and Yazdanbakhsh, 2003).

Furthermore, the large variation in treatment regimens employed in mass-treatment programmes, including the drug administered, number of treatments (single or repeated dose), age-ranges targeted (e.g. school-age children, whole population) and method of administration (e.g. school-based, hospital/clinic-based), is also a potential source of variation in host immunity within endemic populations. Notably, many treatment programmes exclude children under the age of 5 due to a perceived risk of side-effects, despite evidence that children can become both infected and a source of transmission from a very young age (Opara et al. 2007). Most also employ single-dose regimens, despite evidence that repeated treatment may be more effective at augmenting protective immunity (Black et al. 2010) potentially by periodically 'boosting' development of immunological memory (Woolhouse and Hagan, 1999). Whilst the long-term effects of antihelminthic treatment on the host acquired immune response remain unclear, the desired reduction in parasite prevalence and transmission inevitably impacts upon helminth immunoepidemiology.

\section{CO-INFECTION}

Co-infection adds a further level of complexity to host-pathogen interactions and is highly prevalent in some communities, particularly in sub-Saharan Africa (Raso et al. 2004; Brooker et al. 2006). Here we focus on how co-infections of particular public health significance contribute to heterogeneity in the anti-helminth immune response and how these effects vary depending on the species of helminth infection.

\section{Helminth-helminth co-infection}

Certain combinations of helminth co-infection are more common in human populations than others, notably several nematode pairs including: A. lumbricoides and T. trichiura (Faulkner et al. 2005; Ellis et al. 2007), A. lumbricoides and hookworm (Fleming et al. 2006) and O.volvulus and T. trichiura (Faulkner et al. 2005). Interactions between schistosomes and nematodes in co-infection are more variable, with evidence for co-aggregation with hookworms (Fleming et al. 2006) and T. trichiura (Ellis et al. 2007), but no significant association with A. lumbricoides infection intensity (Tchuem Tchuente et al. 2003; Fleming et al. 2006; Ellis et al. 2007). Coinfection also tends to be associated with higher worm burdens than those seen in single species infections (Tchuem Tchuente et al. 2003). A. lumbricoides- $T$. trichiura co-infected individuals were also found to have higher $\operatorname{IgG} 4: \mathrm{IgE}$ ratios than their singly-infected counterparts (Figueiredo et al. 2010).

Several explanations for the variable effect of one helminth species on the likelihood of co-infection with another have been proposed, although it is unlikely that these factors act in isolation. Firstly, similarities in parasite life cycle might mean that certain species share common behavioural or genetic risk factors for infection (Ellis et al. 2007; Pullan et al. 2008). Alternatively, since studies in animals and humans show that patent infection with one helminth species can depress both the humoral and cellular responses of the host to challenge by other parasites 
(Brady et al. 1999; Correa-Oliveira et al. 2002) it is possible that these synergistic interactions result from non-specific 'bystander suppression' (Brady et al. 1999) or immunosuppression directed against crossreactive antigens expressed by closely-related species (Geiger et al. 2002). S. mansoni-exposed but patently uninfected Brazilian subjects, identified by egg and adult worm-specific antibodies, were found to have impaired responses to Ascaris spp. and hookworm infections (Correa-Oliveira et al. 2002), suggesting that prior exposure to schistosomiasis may have a lasting impact on host responses to other helminths. Experimental studies comparing $S$. mansoni infection with antigen (adult worm and egg homogenates) administration, suggest that immunosuppressive mechanisms rely on the presence of active infection (Osada and Kanazawa, 2010). However there is a lack of data on the effect of exposure to one parasite on the immunobiology of subsequent infection with a different species. It is conceivable that, even after clearance of adult worms, sequestration of eggs in host tissues, cellular memory responses to crossreactive antigens and impaired organ-function resulting from cumulative morbidity may all affect the response to subsequent helminthiases.

\section{Helminth-malaria co-infection}

Malaria is a predominantly intracellular protozoan infection and has a markedly different immunobiology to that of helminths. The host response to malaria is characterized by inflammatory cytokines causing periodic fevers and immune-mediated pathology and, though protective immunity is yet to be fully characterized, clearance of blood-stage infection positively correlates with titres of variant-specific cytophilic antibodies, particularly IgG3 (Cavanagh et al. 2004).

Studies of the effect of malaria on immune responses to helminths are rare and tend to focus on the anti-malarial, rather than anti-helminth immune response. However, work on schistosomiasis-malaria co-infections indicate distinct effects on humoral and cellular responses (Mutapi et al. 2000; Wilson et al. 2008). On the one hand, co-infection has been associated with elevated titres of schistosome egg-specific IgE and IgG3 (Mutapi et al. 2000), indicating that acute inflammatory responses to malaria may reverse helminth-mediated immune hyporesponsiveness. Consistent with this hypothesis, skewing of $\mathrm{T}$ cell responses by malaria can exacerbate liver and spleen pathology due to deficient regulation of schistosome egg-specific regulatory responses (Wilson et al. 2008). Recent schistosome-malaria co-infection studies also show that co-infected children do not differ from singly infected children in their absolute numbers of circulating Tregs, but do exhibit reduced proportions of memory Tregs (Muok et al. 2009).
Both elevated malaria-specific $\operatorname{IgG} 3$ and high $S$. mansoni egg counts are risk factors for splenomegaly (Booth et al. 2004b), suggesting that both severity of infection and host immunoreactivity contribute to the clinical outcome of malaria-schistosome coinfection (Diallo et al. 2004).

In individuals concurrently infected with GI nematodes and malaria, the inflammatory response to Plasmodium spp. might be expected to blunt Th2 effector responses involved in clearance of adult nematodes (Mountford and Pearlman, 1998). For example, N. americanus-specific Th2 effector cytokine and total $\mathrm{IgE}$ responses were lower in Papua New Guinean subjects co-infected with malaria, despite no observable effect on hookworm-specific IFN $\gamma$ or cell proliferation (Quinnell et al. 2004). The same study found evidence for malaria and hookworm-mediated suppression of cell proliferation, but not effector cytokine secretion, in response to bacterial antigens (Quinnell et al. 2004). Thus, malaria co-infection can limit the effector response to hookworm, but may not significantly affect hookworm-mediated immunosuppressive mechanisms. Conversely, in a Malian study of malaria- $W$. bancroft $i$ co-infection, filariasis was significantly associated with elevated total and malaria-specific IL-10 and reduced IFN $\gamma$ (Metenou et al. 2009). As more coinfection studies are conducted it will become possible to more directly compare effects of malaria on the acquired immune responses mounted against different helminth species.

\section{Helminth-HIV co-infection}

Human Immunodeficiency Virus (HIV) is a lymphotrophic virus that replicates in CD4 + T cells leading to incremental abrogation of this cell population and progression to Acquired Immune Deficiency Syndrome (AIDS). Both HIV and helminth infection can be considered as immunocompromising infections, and it could therefore be predicted that these effects would synergise to the detriment of co-infected hosts.

Although co-infection studies tend to focus on immune responses to HIV, there is some evidence for heterogeneity in the reciprocal effects of HIV on helminth immunobiology. For example, HIV infection is associated with up-regulation of CTLA-4 expression and anergy, which might enhance helminth-mediated Treg induction and immune evasion (Steel and Nutman, 2003; Leng et al. 2006). Severe immunosuppression in advanced HIV/AIDS is also linked to abnormally high intensity Strongyloides spp. infections due to increased rates of auto-infection and, in some regions, strongyloidiasis is considered to be an AIDS-related opportunistic infection (Meamar et al.2007). Furthermore, low CD4 + T cell counts in HIV seropositive individuals has been associated 
with increased tissue sequestration of schistosome eggs (Karanja et al. 1997), although the relative impact that this has on host pathology has not been investigated.

In addition to generalized immunosuppression, HIV co-infections are negatively correlated with worm-specific effector cytokine responses (Sentongo et al. 1998) and may therefore reduce clearance of both adult and immature worms. HIV-positive patients co-infected with $S$. mansoni had lower measurable agonist-specific IL-4 and parasite and agonist-specific IL-10 than their HIV-negative counterparts, but had similar levels of IFN $\gamma$ (Mwinzi et al. 2001). This finding was linked to an increased Th1: Th2 effector cytokine ratio in HIV-positive individuals (Mwinzi et al. 2001), which may result from preferential infection and abrogation of activated Th2 cells relative to Th1 and naïve T cells (Maggi et al. 1994).

Disruption of $\mathrm{CD} 4+\mathrm{T}$ cell polarization and regulatory mechanisms might be predicted to exacerbate helminth-related pathologies (Maggi et al. 1994; Booth et al. 2004a), particularly in GI infections which require robust Th2 cytokine responses for clearance. However, very few studies of nematodeHIV co-infected populations have been conducted to date. HIV co-infection with schistosomiasis did not affect anti-helminthic treatment efficacy in a Kenyan cohort with high intensity $S$. mansoni infections (Karanja et al. 1998). Researchers in the latter study hypothesized that these findings were partly due to schistosomiasis preceding HIV infection and that subsequent co-infection did not affect pre-existing immune responses to schistosome antigens (Secor et al. 2004). The latter is of particular interest given that HIV is most prevalent in sexually-active adults and thus co-infections tend to arise after initial exposure to helminth infections, which peak in intensity in childhood. Thus, the stage of HIV infection (and associated degree of immunosuppression) and population-specific age-infection intensity distributions of different helminthiases are potential sources of heterogeneity and should be considered when investigating the immunobiology of co-infections.

\section{CONCLUSIONS}

Parasitic helminths present a diverse challenge to the immune system. Their large proteome and broad-range of antigens alone may partially explain the slow development of resistance to helminthiases (Yazdanbakhsh and Sacks, 2010). Furthermore, the stage-specific challenges (Day et al. 1991a,b; MacDonald et al. 2002) and genetic diversity within single species infections (Galvani, 2005) can lead to heterogeneity in anti-helminth immune responses in an individual host.

When comparing different species of helminth it is clear that immune-heterogeneity can transcend phylogenetic delineations, particularly with respect to parasite life-span and intra-host niche. Long-lived parasites and species inhabiting host tissues can only exist incognito via sophisticated immunosuppressive mechanisms that may compromise fecundity and transmission of infection (Karanja et al. 1997; Maizels and Yazdanbakhsh, 2003; Brattig, 2004). Short-lived and GI parasites face different challenges resulting in characteristic immunobiology. Whilst immunity to the tissue-dwelling nematodes is associated with a mixed $\mathrm{CD} 4+\mathrm{T}$ cell immune response (Turaga et al. 2000), expulsion of GI nematode species is more specifically Th2-dependent ('Turner et al. 2003). Few studies have directly compared immune responses to GI nematodes, filarial nematodes and Schistosoma spp. in single-infections, potentially due to the high prevalence of co-infection, meaning that many of the hypothesized sources of interspecific immune heterogeneities remain to be empirically tested.

Unlike in experimental animal infections, acquired immune heterogeneity in natural infections also arises from host variables. Genetic polymorphism in the human immune system inevitably translates into heterogeneous expression of cellular and humoral responses, as is evident in clustering of immune responses within populations and individual families (Quinnell, 2003; Ellis et al. 2007). The relatively recent discovery of new $\mathrm{CD} 4+\mathrm{T}$ cell subclasses and identification of further plasticity in innate effector cells has led to re-evaluation of how helminths interact with their human host (Diaz and Allen, 2007; Jenkins and Allen, 2010). Furthermore, the influence that host exposure-history, antihelminthic treatment and co-infection have on anti-helminth responses indicates that immune heterogeneity arises not from the host and parasite in isolation, but also from the environment in which they interact.

Despite the diversity of helminth species and their host populations identifying the immunological mechanisms underlying these distinctions has been a challenge for field studies. Helminth-specific immune responses become activated and polarized at a very young age (Eloi-Santos et al. 1989; Lammie et al. 1991; Novato-Silva et al. 1992; Steel et al. 1994; King et al. 1998). However, field studies often exclude individuals under the age of 5 , focusing instead on older individuals in the chronic stage of infection with a more ambiguous exposure and treatment history. In addition, whilst co-evolution of humans and helminths has clearly led to shared features of an anti-macroparasite response (Jackson et al. 2009), it is also possible that peripheral sampling methods, co-infection and long-term systemic disease may disguise integral differences in human immune responses (Hayes et al. 2004). The cellular targets of systemic and highly pleiotropic cytokines and sitespecific immune responses are particularly difficult to 
define in peripheral blood samples. Thus, in addition to expansion of elegant in vitro cellular assays, a wider range of immune correlates should be measured in the field to give a broader characterization of the host immune 'phenotype' in which these cells act.

Anthropophilic helminths are both evolutionarily ancient and alarmingly prevalent (Hotez et al. 2008), yet the immune responses mounted against them and the best means of treating infection remain unclear. Characterization of risk factors for infection and morbidity requires immunological measures to be considered in the context of host and environmental variables, which can be as influential as those of the parasite, and in some cases more so (Jackson et al. 2004a; Ellis et al. 2007).

\section{ACKNOWLEDGEMENTS}

The authors would like to thank the American fournal of Tropical Medicine and Hygiene, Allen Press Publishing Services, the University of Chicago Press, Elsevier and John Wiley and Sons Ltd for permission to re-print published material. Financial support was provided by the Biotechnology and Biological Sciences Research Council, The Cunningham Trust, The Carnegie Trust for the Universities of Scotland, University of Edinburgh's Moray Endowment Fund, Tenovus Scotland and The Wellcome Trust (Grant numbers WT082028MA, 076561 and 090281). The Wellcome Trust also provided funding for this article to be made available in an Open Access environment.

\section{REFERENCES}

Acosta, L. P., McManus, D. P., Aligui, G. D. L., Olveda, R. M. and Tiu, W. U. (2004). Antigen-specific antibody isotype patterns to Schistosoma japonicum recombinant and native antigens in a defined population in Leyte, The Philippines. American Fournal of Tropical Medicine and Hygiene 70, 549-555.

Anderson, R. M. and May, R. M. (1985). Helminth infections of humans - mathematical-models, population-dynamics, and control. Advances in Parasitology 24, 1-101.

Anderson, R. M. and May, R. M. (1992). Infectious Diseases of Humans. Dynamics and Control, Oxford University Press, Oxford, UK.

Babu, S., Bhat, S. Q., Kumar, N. P., Lipira, A. P., Kumar, S., Karthick, C., Kumaraswami, V. and Nutman, T. B. (2009). Filarial lymphedema is characterized by antigen-specific Th1 and Th17 proinflammatory responses and a lack of regulatory T cells. PLoS Neglected Tropical Diseases 3, 1-9.

Bager, P., Arnved, J., Ronborg, S., Wohlfahrt, J., Poulsen, L. K., Westergaard, T., Petersen, H. W., Kristensen, B., Thamsborg, S., Roepstorff, A., Kape1, C. and Melbye, M. (2010). Trichuris suis ova therapy for allergic rhinitis: A randomized, double-blind, placebo-controlled clinical trial. Fournal of Allergy and Clinical Immunology 125, 123-130.

Berriman, M., Haas, B. J., LoVerde, P. T., Wilson, R. A., Dillon, G. P., Cerqueira, G. C.,
Mashiyama, S. T., Al-Lazikani, B., Andrade, L. F., Ashton, P. D., Aslett, M. A., Bartholomeu, D. C., Blandin, G., Caffrey, C. R., Coghlan, A., Coulson, R., Day, T. A., Delcher, A., DeMarco, R., Djikeng, A., Eyre, T., Gamble, J. A., Ghedin, E., Gu, Y., Hertz-Fowler, C., Hirai, H., Hirai, Y., Houston, R., Ivens, A., Johnston, D. A., Lacerda, D., Macedo, C. D., McVeigh, P., Ning, Z. M., Oliveira, G., Overington, J. P., Parkhill, J., Pertea, M., Pierce, R. J., Protasio, A. V., Quail, M. A., Rajandream, M. A., Rogers, J., Sajid, M., Salzberg, S. L., Stanke, M., Tivey, A. R., White, O., Williams, D. L., Wortman, J., Wu, W. J., Zamanian, M., Zerlotini, A., Fraser-Liggett, C. M., Barrell, B. G. and El-Sayed, N. M. (2009).

The genome of the blood fluke Schistosoma mansoni. Nature, London 460, 352-365.

Bethony, J., Williams, J. T., Blangero, J., Kloos, H., Gazzinelli, A., Soares, B., Coelho, L., AlvesFraga, L., Williams-Blangero, S., Loverde, P. T. and Correa-Oliveira, R. (2002). Additive host genetic factors influence fecal egg excretion rates during Schistosoma mansoni infection in a rural area in Brazil. American Fournal of Tropical Medicine and Hygiene 67, 336-343

Black, C. L., Mwinzi, P. N., Muok, E. M., Abudho, B., Fitzsimmons, C. M., Dunne, D. W., Karanja, D. M., Secor, W. E. and Colley, D. G. (2010). Influence of exposure history on the immunology and development of resistance to human Schistosomiasis mansoni. PLoS Neglected Tropical Diseases 4, e637.

Booth, M., Mwatha, J. K., Joseph, S., Jones, F. M., Kadzo, H., Ireri, E., Kazibwe, F., Kemijumbi, J., Kariuki, C., Kimani, G., Ouma, J. H., Kabatereine, N. B., Vennervald, B. J. and Dunne, D. W. (2004a). Periportal fibrosis in human Schistosoma mansoni infection is associated with low IL-10, low IFN-gamma, high TNF-alpha, or low RANTES, depending on age and gender. Fournal of Immunology 172, 1295-1303.

Booth, M., Vennervald, B. J., Kenty, L., Butterworth, A. E., Kariuki, H. C., Kadzo, H., Ireri, E., Amaganga, C., Kimani, G., Mwatha, J. K., Otedo, A., Ouma, J. H., Muchiri, E. and Dunne, D. W. (2004b). Micro-geographical variation in exposure to Schistosoma mansoni and malaria, and exacerbation of splenomegaly in Kenyan school-aged children. BMC Infectious Diseases 4, 13.

Bradley, M. and Chandiwana, S. K. (1990). Age-dependency in predisposition to hookworm infection in the Burma valley area of Zimbabwe. Transactions of the Royal Society of Tropical Medicine and Hygiene 84, 826-828.

Brady, M. T., O'Neill, S. M., Dalton, J. P. and Mills, K. H. G. (1999). Fasciola hepatica suppresses a protective Th1 response against Bordetella pertussis. Infection and Immunity 67, 5372-5378.

Brattig, N. W. (2004). Pathogenesis and host responses in human onchocerciasis: impact of Onchocerca filariae and Wolbachia endobacteria. Microbes and Infection 6, 113-128.

Brooker, S., Clements, A. C., Hotez, P. J., Hay, S. I., Tatem, A. J., Bundy, D. A. and Snow, R. W. (2006). The co-distribution of Plasmodium falciparum and 
hookworm among African schoolchildren. Malaria Fournal 5, 99.

Brooker, S., Donnelly, C. A. and Guyatt, H. L. (2000). Estimating the number of helminthic infections in the Republic of Cameroon from data on infection prevalence in schoolchildren. Bulletin of the World Health Organization 78, 1456-1465.

Bundy, D. A., Cooper, E. S., Thompson, D. E., Didier, J. M. and Simmons, I. (1988). Effect of age and initial infection intensity on the rate of reinfection with Trichuris trichiura after treatment. Parasitology 97, 469-476.

Caldas, I. R., Correa-Oliveira, R., Colosimo, E., Carvalho, O. S., Massara, C. L., Colley, D. G. and Gazzinelli, G. (2000). Susceptibility and resistance to Schistosoma mansoni reinfection: Parallel cellular and isotypic immunologic assessment. American Fournal of Tropical Medicine and Hygiene 62, 57-64.

Cavanagh, D. R., Dodoo, D., Hviid, L., Kurtzhals, J. A., Theander, T. G., Akanmori, B. D., Polley, S., Conway, D. J., Koram, K. and McBride, J. S. (2004). Antibodies to the N-terminal block 2 of Plasmodium falciparum merozoite surface protein 1 are associated with protection against clinical malaria. Infection and Immunity 72, 6492-6502.

Chandiwana, S. K., Woolhouse, M. E. J. and Bradley, M. (1991). Factors affecting the intensity of reinfection with Schistosoma haematobium following treatment with praziquantel. Parasitology 102, 73-83.

Cooper, P. J., Chico, M. E., Sandoval, C., Espinel, I., Guevara, A., Kennedy, M. W., Urban Jr, J. F., Griffin, G. E. and Nutman, T. B. (2000). Human infection with Ascaris lumbricoides is associated with a polarized cytokine response. Fournal of Infectious Diseases 182, 1207-1213.

Cooper, P. J., Chico, M. E., Sandoval, C. and Nutman, T. B. (2004). Atopic phenotype is an important determinant of immunoglobulin E-mediated inflammation and expression of $\mathrm{T}$ helper cell type 2 cytokines to ascaris antigens in children exposed to Ascariasis. Fournal of Infectious Diseases 190, 1338-1346.

Correa-Oliveira, R., Golgher, D. B., Oliveira, G. C., Carvalho, O. S., Massara, C. L., Caldas, I. R., Colley, D. G. and Gazzinelli, G. (2002). Infection with Schistosoma mansoni correlates with altered immune responses to Ascaris lumbricoides and hookworm. Acta Tropica 83, 123-132.

Correale, J. and Farez, M. (2009). Helminth antigens modulate immune responses in cells from multiple sclerosis patients through TLR2-dependent mechanisms. Fournal of Immunology 183, 5999-6012.

Coutinho, H. M., Acosta, L. P., Wu, H. W., McGarvey, S. T., Su, L., Langdon, G. C., Jiz, M. A., Jarilla, B., Olveda, R. M., Friedman, J. F. and Kurtis, J. D. (2007). Th2 cytokines are associated with persistent hepatic fibrosis in human Schistosoma japonicum infection. Fournal of Infectious Diseases 195, 288-295.

Croese, J., O’Neil, J., Masson, J., Cooke, S., Melrose, W., Pritchard, D. and Speare, R. (2006). A proof of concept study establishing Necator americanus in Crohn's patients and reservoir donors. Gut 55, 136-137.
Dardalhon, V., Awasthi, A., Kwon, H., Galileos, G., Gao, W., Sobel, R. A., Mitsdoerffer, M., Strom, T. B., Elyaman, W., Ho, I. C., Khoury, S., Oukka, M. and Kuchroo, V. K. (2008). IL-4 inhibits TGF-betainduced Foxp3(+) T cells and, together with TGF-beta, generates IL-9(+) IL-10(+) Foxp3(-) effector T cells. Nature Immunology 9, 1347-1355.

Day, K. P., Gregory, W. F. and Maizels, R. M. (1991a). Age-specific acquisition of immunity to infective larvae in a bancroftian filariasis endemic Area of Papua-New-Guinea. Parasite Immunology 13, 277-290.

Day, K. P., Grenfell, B., Spark, R., Kazura, J. W. and Alpers, M. P. (1991b). Age-specific patterns of change in the dynamics of Wuchereria bancrofti infection in Papua-New-Guinea. American Fournal of Tropical Medicine and Hygiene 44, 518-527.

De Jesus, A. R., Araujo, I., Bacellar, O., Magalhaes, A., Pearce, E., Harn, D., Strand, M. and Carvalho, E. M. (2000). Human immune responses to Schistosoma mansoni vaccine candidate antigens. Infection and Immunity 68, 2797-2803.

Deenick, E. K. and Tangye, S. G. (2007). Autoimmunity: IL-21: a new player in Th17-cell differentiation. Immunology and Cell Biology 85, 503-505.

Demeure, C. E., Brahimi, K., Hacini, F., Marchand, F., Peronet, R., Huerre, M., St-Mezard, P., Nicolas, J. F., Brey, P., Delespesse, G. and Mecheri, S. (2005). Anopheles mosquito bites activate cutaneous mast cells leading to a local inflammatory response and lymph node hyperplasia. Fournal of Immunology 174, 3932-3940.

Demeure, C. E., Rihet, P., Abel, L., Ouattara, M., Bourgois, A. and Dessein, A. J. (1993). Resistance to Schistosoma mansoni in humans - influence of the $\mathrm{IgE} / \mathrm{IgG} 4$ balance and $\mathrm{IgG} 2$ in immunity to reinfection after chemotherapy. Fournal of Infectious Diseases 168, 1000-1008.

Dessein, A., Kouriba, B., Eboumbou, C., Dessein, H., Argiro, L., Marquet, S., Elwali, N. E. M. A., Rodrigues, V., Li, Y.S., Doumbo, O. and Chevillard, C. (2004). Interleukin-13 in the skin and interferon-gamma in the liver are key players in immune protection in human schistosomiasis. Immunological Reviews 201, 180-190.

Diallo, T. O., Remoue, F., Schacht, A. M., Charrier, N., Dompnier, J. P., Pillet, S., Garraud, O., N'Diaye, A. A., Capron, A., Capron, M. and Riveau, G. (2004). Schistosomiasis co-infection in humans influences inflammatory markers in uncomplicated Plasmodium falciparum malaria. Parasite Immunology 26, 365-369.

Diaz, A. and Allen, J. E. (2007). Mapping immune response profiles: The emerging scenario from helminth immunology. European Fournal of Immunology 37, 3319-3326.

Doetze, A., Satoguina, J., Burchard, G., Rau, T., Loliger, C., Fleischer, B. and Hoerauf, A. (2000). Antigen-specific cellular hyporesponsiveness in a chronic human helminth infection is mediated by Th3/Tr1-type cytokines IL-10 and transforming growth factor-beta but not by a Th1 to Th2 shift. International Immunology 12, 623-630. 
Dorris, M., De Ley, P. and Blaxter, M. L. (1999). Molecular analysis of nematode diversity and the evolution of parasitism. Parasitology Today 15, 188-193.

Ellis, M. K., Raso, G., Li, Y. S., Rong, Z., Chen, H. G. and McManus, D. P. (2007). Familial aggregation of human susceptibility to co- and multiple helminth infections in a population from the Poyang Lake region, China. International Fournal for Parasitology 37, 1153-1161.

Eloi-Santos, S. M., Novato-Silva, E., Maselli, V. M., Gazzinelli, G., Colley, D. G. and Correa-

Oliveira, R. (1989). Idiotypic sensitization in utero of children born to mothers with schistosomiasis or Chagas' disease. Fournal of Clinical Investigation 84, 1028-1031.

ElRidi, R., Ismail, S., Gaafar, T. and ElDemellawy, M. (1997). Differential responsiveness of humans with early-stage schistosomiasis haematobium to Schistosoma haematobium soluble adult-worm and egg antigens. Parasitology Research 83, 471-477.

Else, K. J. (2005). Have gastrointestinal nematodes outwitted the immune system? Parasite Immunology 27, 407-415.

Everts, B., Perona-Wright, G., Smits, H. H., Hokke, C. H., van der Ham, A. J., Fitzsimmons, C. M., Doenhoff, M. J., van der Bosch, J., Mohrs, K., Haas, H., Mohrs, M., Yazdanbakhsh, M. and Schramm, G. (2009). Omega-1, a glycoprotein secreted by Schistosoma mansoni eggs, drives Th2 responses. Fournal of Experimental Medicine 206, 1673-1680.

Falcone, F. H. and Pritchard, D. I. (2005). Parasite role reversal: worms on trial. Trends in Parasitology 21, 157-160.

Faulkner, H., Turner, J., Behnke, J., Kamgno, J., Rowlinson, M. C., Bradley, J. E. and Boussinesq, M. (2005). Associations between filarial and gastrointestinal nematodes. Transactions of the Royal Society of Tropical Medicine and Hygiene 99, 301-312.

Faulkner, H., Turner, J., Kamgno, J., Pion, S. D., Boussinesq, M. and Bradley, J. E. (2002). Age- and infection intensity-dependent cytokine and antibody production in human trichuriasis: the importance of $\mathrm{IgE}$. Fournal of Infectious Diseases 185, 665-672.

Figueiredo, C. A., Barreto, M. L., Rodrigues, L. C., Cooper, P. J., Silva, N. B., Amorim, L. D. and Alcantara-Neves, N. M. (2010). Chronic intestinal helminth infections are associated with immune hyporesponsiveness and induction of a regulatory network. Infection and Immunology 78, 3160-3167.

Finkelman, F. D., Shea-Donohue, T., Morris, S. C., Gildea, L., Strait, R., Madden, K. B., Schopf, L. and Urban, J. F. (2004). Interleukin-4- and interleukin-13-mediated host protection against intestinal nematode parasites. Immunological Reviews 201, 139-155.

Fisher, A. C. (1934). A study of the schistosomiasis of the Stanleyville district of the Belgian congo.

Transactions of the Royal Society of Tropical Medicine and Hygiene 28, 277-306.

Fitzpatrick, J. M., Peak, E., Perally, S., Chalmers, I. W., Barrett, J., Yoshino, T. P., Ivens, A. C. and Hoffmann, K. F. (2009). Anti-schistosomal intervention targets identified by lifecycle transcriptomic analyses. PLoS Neglected Tropical Diseases 3, 543.

Fleming, F. M., Brooker, S., Geiger, S. M., Caldas, I. R., Correa-Oliveira, R., Hotez, P. J. and Bethony, J. M. (2006). Synergistic associations between hookworm and other helminth species in a rural community in Brazil. Tropical Medicine $\xi^{\circ}$ International Health 11, 56-64.

Flohr, C., Quinnell, R. J. and Britton, J. (2009). Do helminth parasites protect against atopy and allergic disease? Clinical and Experimental Allergy 39, 20-32.

Fulford, A. J. C., Butterworth, A. E., Ouma, J. H. and Sturrock, R. F. (1995). A statistical approach to schistosome population dynamics and estimation of the life-span of Schistosoma mansoni in man. Parasitology 110, 307-316.

Fumagalli, M., Pozzoli, U., Cagliani, R., Comi, G. P., Riva, S., Clerici, M., Bresolin, N. and Sironi, M. (2009). Parasites represent a major selective force for interleukin genes and shape the genetic predisposition to autoimmune conditions. Fournal of Experimental Medicine 206, 1395-1408. doi: 10.1084/jem.20082779.

Galvani, A. P. (2005). Age-dependent epidemiological patterns and strain diversity in helminth parasites. Fournal of Parasitology 91, 24-30.

Gandhi, N. S., Chen, J. Z., Khoshnood, K., Xing, F. Y., Li, S. W., Liu, Y. R., Zhan, B., Xue, H. C., Tong, C. J., Wang, Y., Wang, W. S., He, D. X., Chen, C., Xiao, S. H., Hawdon, J. M. and Hotez, P. J. (2001). Epidemiology of Necator americanus hookworm infections in Xiulongkan village, Hainan province, China: High prevalence and intensity among middle-aged and elderly residents. Fournal of Parasitology 87, 739-743.

Geiger, S. M., Caldas, I. R., Mc Glone, B. E., Campi-Azevedo, A. C., De Oliveira, L. M., Brooker, S., Diemert, D., Correa-Oliveira, R. and Bethony, J. M. (2007). Stage-specific immune responses in human Necator americanus infection. Parasite Immunology 29, 347-358.

Geiger, S. M., Massara, C. L., Bethony, J., Soboslay, P. T., Carvalho, O.S. and Correa-Oliveira, R. (2002). Cellular responses and cytokine profiles in Ascaris lumbricoides and Trichuris trichiura infected patients. Parasite Immunology 24, 499-509.

Ghedin, E., Wang, S. L., Spiro, D., Caler, E., Zhao, Q., Crabtree, J., Allen, J. E., Delcher, A. L., Guiliano, D. B., Miranda-Saavedra, D., Angiuoli, S. V., Creasy, T., Amedeo, P., Haas, B., El-Sayed, N. M., Wortman, J. R., Feldblyum, T., Tallon, L., Schatz, M., Shumway, M., Koo, H., Salzberg, S. L., Schobel, S., Pertea, M., Pop, M., White, O., Barton, G. J., Carlow, C. K. S., Crawford, M. J., Daub, J., Dimmic, M. W., Estes, C. F., Foster, J. M., Ganatra, M., Gregory, W. F., Johnson, N. M., Jin, J. M., Komuniecki, R., Korf, I., Kumar, S., Laney, S., Li, B. W., Li, W., Lindblom, T. H., Lustigman, S., Ma, D., Maina, C. V., Martin, D. M. A., McCarter, J. P., McReynolds, L., Mitreva, M., Nutman, T. B., Parkinson, J., PeregrinAlvarez, J. M., Poole, C., Ren, Q. H., Saunders, L., Sluder, A. E., Smith, K., Stanke, M., Unnasch, T. R., 
Ware, J., Wei, A. D., Weil, G., Williams, D. J., Zhang, Y. H., Fraser-Liggett, C., Slatko, B., Blaxter, M. L. and Scott, A. L. (2007). Draft genome of the filarial nematode parasite Brugia malayi. Science 317, 1756-1760.

Gomez-Escobar, N., Gregory, W. F. and

Maizels, R. M. (2000). Identification of tgh-2, a filarial nematode homolog of Caenorhabditis elegans daf-7 and human transforming growth factor beta, expressed in microfilarial and adult stages of Brugia malayi.

Infection and Immunity 68, 6402-6410.

Gryseels, B., Polman, K., Clerinx, J. and Kestens, L. (2006). Human schistosomiasis. Lancet 368, 1106-1118.

Hagan, P., Blumenthal, U. J., Dunn, D., Simpson, A. J. G. and Wilkins, H. A. (1991)

Human IgE, IgG4 and resistance to reinfection with Schistosoma haematobium. Nature, London 349, 243-245.

Harcus, Y. M., Parkinson, J., Fernandez, C., Daub, J., Selkirk, M. E., Blaxter, M. L. and Maizels, R. M. (2004). Signal sequence analysis of expressed sequence tags from the nematode Nippostrongylus brasiliensis and the evolution of secreted proteins in parasites. Genome Biology 5, R39.

Hayes, K. S., Bancroft, A. J. and Grencis, R. K. (2004). Immune-mediated regulation of chronic intestinal nematode infection. Immunological Reviews 201, 75-88.

He, Y. X., Chen, L. and Ramaswamy, K. (2002). Schistosoma mansoni, S. haematobium, and S. japonicum: early events associated with penetration and migration of schistosomula through human skin. Experimental Parasitology 102, 99-108.

He, Y. X., Salafsky, B. and Ramaswamy, K. (2005). Comparison of skin invasion among three major species of Schistosoma. Trends in Parasitology 21, 201-203.

Henri, S., Chevillard, C., Mergani, A., Paris, P., Gaudart, J., Camilla, C., Dessein, H., Montero, F., Elwali, N. E., Saeed, O. K., Magzoub, M. and Dessein, A. J. (2002). Cytokine regulation of periportal fibrosis in humans infected with Schistosoma mansoni: IFN-gamma is associated with protection against fibrosis and TNF-alpha with aggravation of disease. Fournal of Immunology 169, 929-936.

Hoekstra, R., Visser, A., Otsen, M., Tibben, J., Lenstra, J. A. and Roos, M. H. (2000). EST sequencing of the parasitic nematode Haemonchus contortus suggests a shift in gene expression during transition to the parasitic stages. Molecular and Biochemical Parasitology 110, 53-68.

Hoerauf, A., Kruse, S., Brattig, N. W., Heinzmann, A., Mueller-Myhsok, B. and Deichmann, K. A. (2002). The variant Arg110Gln of human IL-13 is associated with an immunologically hyper-reactive form of onchocerciasis (sowda). Microbes and Infection 4, 37-42.

Hoffmann, K. F., Wynn, T. A. and Dunne, D. W. (2002). Cytokine-mediated host responses during schistosome infections; walking the fine line between immunological control and immunopathology. Advances in Parasitology 52, 265-307.

Hotez, P. J., Brindley, P. J., Bethony, J. M., King, C. H., Pearce, E. J. and Jacobson, J. (2008). Helminth infections: the great neglected tropical diseases. Fournal of Clinical Investigation 118, 1311-1321.

Hunt, P. W., Knox, M. R., Le Jambre, L. F., McNally, J. and Anderson, L. J. (2008). Genetic and phenotypic differences between isolates of Haemonchus contortus in Australia. International Fournal for Parasitology 38, 885-900.

Jackson, J. A., Friberg, I. M., Little, S. and Bradley, J. E. (2009). Review series on helminths, immune modulation and the hygiene hypothesis: immunity against helminths and immunological phenomena in modern human populations: coevolutionary legacies? Immunology 126, 18-27.

Jackson, J. A., Turner, J. D., Rentoul, L., Faulkner, H., Behnke, J. M., Hoyle, A., Grencis, R. K., Else, K. J., Kamgno, J., Bradley, J. E. and Boussinesq, M. (2004a). Cytokine response profiles predict speciesspecific infection patterns in human GI nematodes. International Fournal for Parasitology 34, 1237-1244.

Jackson, J. A., Turner, J. D., Rentoul, L., Faulkner, H., Behnke, J. M., Hoyle, M., Grencis, R. K., Else, K. J., Kamgno, J., Boussinesq, M. and Bradley, J. E. (2004b). T helper cell type 2 responsiveness predicts future susceptibility to gastrointestinal nematodes in humans. Fournal of Infectious Diseases 190, 1804-1811.

Jaoko, W. G., Simonsen, P. E., Meyrowitsch, D. W., Estambale, B. B. A., Malecela-Lazaro, M. N. and Michael, E. (2006). Filarial-specific antibody response in east African Bancroftian filariasis: Effects of host infection, clinical disease, and filarial endemicity. American Fournal of Tropical Medicine and Hygiene 75, 97-107.

Jenkins, S. J. and Allen, J. E. (2010). Similarity and diversity in macrophage activation by nematodes, trematodes, and cestodes. Fournal of Biomedicine and Biotechnology 2010, 262609.

Jenkins, S. J., Hewitson, J. P., Jenkins, G. R. and Mountford, A. P. (2005). Modulation of the host's immune response by schistosome larvae. Parasite Immunology 27, 385-393.

Jolly, E. R., Chin, C. S., Miller, S., Bahgat, M. M., Lim, K. C., DeRisi, J. and McKerrow, J. H. (2007). Gene expression patterns during adaptation of a helminth parasite to different environmental niches. Genome Biology 8, R65.

Joseph, S., Jones, F. M., Kimani, G., Mwatha, J. K., Kamau, T., Kazibwe, F., Kemijumbi, J., Kabatereine, N. B., Booth, M., Kariuki, H. C., Ouma, J. H., Vennervald, B. J. and Dunne, D. W. (2004). Cytokine production in whole blood cultures from a fishing community in an area of high endemicity for Schistosoma mansoni in Uganda: the differential effect of parasite worm and egg antigens. Infection and Immunity 72, 728-734.

Karanja, D. H. S., Boyer, A. E., Strand, M., Colley, D. G., Nahlen, B. L., Ouma, J. H. and Secor, W. E. (1998). Studies on schistosomiasis in western Kenya: II. Efficacy of praziquantel for treatment of schistosomiasis in persons coinfected with human immunodeficiency virus-1. American Fournal of Tropical Medicine and Hygiene 59, 307-311.

Karanja, D. M. S., Colley, D. G., Nahlen, B. L., Ouma, J. H. and Secor, W. E. (1997). Studies on schistosomiasis in western Kenya .I. Evidence for immune-facilitated excretion of schistosome eggs from patients with Schistosoma mansoni and human immunodeficiency virus coinfections. American Fournal of Tropical Medicine and Hygiene 56, 515-521. 
King, C. H., Blanton, R. E., Muchiri, E. M., Ouma, J. H., Kariuki, H. C., Mungai, P., Magak, P., Kadzo, H., Ireri, E. and Koech, D. K. (2004). Low heritable component of risk for infection intensity and infection-associated disease in urinary schistosomiasis among Wadigo village populations in Coast Province, Kenya. American Fournal of Tropical Medicine and Hygiene 70, 57-62.

King, C. L., Malhotra, I., Mungai, P., Wamachi, A., Kioko, J., Ouma, J. H. and Kazura, J. W. (1998). Cell sensitization to helminthic infection develops in utero in humans. Fournal of Immunology $\mathbf{1 6 0}$, 3578-3584.

Klion, A. D. and Nutman, T. B. (2004). The role of eosinophils in host defense against helminth parasites. Fournal of Allergy and Clinical Immunology 113, 30-37.

Kouriba, B., Chevillard, C., Bream, J. H., Argiro, L., Dessein, H., Arnaud, V., Sangare, L., Dabo, A., Beavogui, A. H., Arama, C., Traore, H. A., Doumbo, O. and Dessein, A. (2005). Analysis of the 5q31-q33 locus shows an association between IL13-1055C/T IL-13-591A/G polymorphisms and Schistosoma haematobium infections. Fournal of Immunology 174, 6274-6281.

Kurowska-Stolarska, M., Kewin, P., Murphy, G., Russo, R. C., Stolarski, B., Garcia, C. C., Komai-Koma, M., Pitman, N., Li, Y. B., McKenzie, A. N. J., Teixeira, M. M., Liew, F. Y. and Xu, D. M. (2008). IL-33 induces antigen-specific IL-5(+) T cells and promotes allergic-induced airway inflammation independent of IL-4. Fournal of Immunology 181, 4780-4790.

Lammie, P. J., Hitch, W. L., Allen, E. M. W., Hightower, W. and Eberhard, M. L. (1991). Maternal filarial infection as risk factor for infection in children. Lancet 337, 1005-1006.

Langley, J. G., Kariuki, H. C., Hammersley, A. P., Ouma, J. H., Butterworth, A. E. and Dunne, D. W. (1994). Human-IgG subclass responses and subclass restriction to Schistosoma mansoni egg antigens. Immunology 83, 651-658.

Leng, Q. B., Bentwich, Z. and Borkow, G. (2006). Increased TGF-beta, Cbl-b and CTLA-4 levels and immunosuppression in association with chronic immune activation. International Immunology 18, 637-644.

Leonardi-Bee, J., Pritchard, D., Britton, J. and Collaboration, P. A. (2006). Asthma and current intestinal parasite infection - Systematic review and meta-analysis. American Fournal of Respiratory and Critical Care Medicine 174, 514-523.

Loukas, A. and Prociv, P. (2001). Immune responses in hookworm infections. Clinical Microbiology Reviews 14, 689-703

MacDonald, A. J., Turaga, P. S. D., HarmonBrown, C., Tierney, T. J., Bennett, K. E., McCarthy, M. C., Simonek, S. C., Enyong, P. A., Moukatte, D. W. and Lustigman, S. (2002).

Differential cytokine and antibody responses to adult and larval stages of Onchocerca volvulus consistent with the development of concomitant immunity. Infection and Immunity 70, 2796-2804.

Maggi, E., Mazzetti, M., Ravina, A., Annunziato, F., De Carli, M., Piccinni, M. P., Manetti, R., Carbonari, M., Pesce, A. M., Del Prete, G. and et al.
(1994). Ability of HIV to promote a TH1 to TH0 shift and to replicate preferentially in $\mathrm{TH} 2$ and $\mathrm{TH} 0$ cells. Science 265, 244-248.

Maizels, R. M. (2009). Exploring the immunology of parasitism - from surface antigens to the hygiene hypothesis. Parasitology 136, 1549-1564.

Maizels, R. M., Bundy, D. A. P., Selkirk, M. E., Smith, D. F. and Anderson, R. M. (1993). Immunological modulation and evasion by helminth parasites in human populations. Nature, London $\mathbf{3 6 5}$, 797-805.

Maizels, R. M., Gomez-Escobar, N., Gregory, W. F., Murray, J. and Zang, X. X. (2001). Immune evasion genes from filarial nematodes. International Fournal for Parasitology 31, 889-898.

Maizels, R. M. and Kurniawan-Atmadja, A. (2002). Variation and polymorphism in helminth parasites. Parasitology 125 (Suppl.) S25-S37.

Maizels, R. M., Pearce, E. J., Artis, D., Yazdanbakhsh, M. and Wynn, T. A. (2009). Regulation of pathogenesis and immunity in helminth infections. Fournal of Experimental Medicine 206, 2059-2066.

Maizels, R. M. and Yazdanbakhsh, M. (2003). Immune regulation by helminth parasites: cellular and molecular mechanisms. Nature Reviews Immunology 3, 733-744.

Malhotra, I., Mungai, P., Wamachi, A., Kioko, J., Ouma, J. H., Kazura, J. W. and King, C. L. (1999). Helminth- and Bacillus Calmette-Guerin-induced immunity in children sensitized in utero to filariasis and schistosomiasis. Fournal of Immunology 162, 6843-6848.

Malhotra, I., Ouma, J., Wamachi, A., Kioko, J., Mungai, P., Omollo, A., Elson, L., Koech, D., Kazura, J. W. and King, C. L. (1997). In utero exposure to helminth and mycobacterial antigens generates cytokine responses similar to that observed in adults. Fournal of Clinical Investigation 99, 1759-1766.

Mayer, L. (2000). Mucosal immunity and gastrointestinal antigen processing. Fournal of Pediatric Gastroenterology and Nutrition 30 (Suppl.), S4-S12.

Meamar, A. R., Rezaian, M., Mohraz, M., Hadighi, R. and Kia, E. B. (2007). Strongyloides stercoralis hyperinfection syndrome in HIV + /AIDS patients in Iran. Parasitology Research 101, 663-665.

Medeiros, M., Figueiredo, J. P., Almeida, M. C., Matos, M. A., Araujo, M. I., Cruz, A. A., Atta, A. M., Rego, M. A. V., De Jesus, A. R., Taketomi, E. A. and Carvalho, E. M. (2003). Schistosoma mansoni infection is associated with a reduced course of asthma. Fournal of Allergy and Clinical Immunology 111, 947-951.

Mestas, J. and Hughes, C. C. W. (2004). Of mice and not men: differences between mouse and human immunology. Fournal of Immunology 172, 2731-2738.

Metenou, S., Dembele, B., Konate, S., Dolo, H., Coulibaly, S. Y., Coulibaly, Y. I., Diallo, A. A., Soumaoro, L., Coulibaly, M. E., Sanogo, D., Doumbia, S. S., Wagner, M., Traore, S. F., Klion, A., Mahanty, S. and Nutman, T. B. (2009). Patent filarial infection modulates malaria-specific type 1 cytokine responses in an IL-10-dependent manner in a filaria/ malaria-coinfected population. Fournal of Immunology 183, 916-924. 
Montenegro, S. N. M., Miranda, P., Mahanty, S., Abath, F. G. C., Teixeira, K. M., Coutinho, E. M., Brinkman, J., Goncalves, I., Domingues, L. A. W., Domingues, A. A. C., Sher, A. and Wynn, T. A. (1999). Cytokine production in acute versus chronic human schistosomiasis mansoni: the cross-regulatory role of interferon-gamma and interleukin 10 in the responses of peripheral blood mononuclear cells and splenocytes to parasite antigens. The Fournal of Infectious Diseases 179, 1502-1514. doi: 10.1086/314748.

Moreno, Y. and Geary, T. G. (2008). Stage- and gender-specific proteomic analysis of Brugia malayi excretory-secretory products. PLoS Neglected Tropical Diseases 2, e326.

Mountford, A. P. and Pearlman, E. (1998). Interleukin-12 and the host response to parasitic helminths; the paradoxical effect on protective immunity and immunopathology. Parasite Immunology 20, 509-517.

Muok, E. M. O., Mwinzi, P. N. M., Black, C. L., Carter, J. M., Ng'ang'a, Z. W., Gicheru, M. M., Secor, W. E., Karanja, D. M. S. and Colley, D. G. (2009). Short report: childhood coinfections with Plasmodium falciparum and Schistosoma mansoni result in lower percentages of activated T cells and $\mathrm{T}$ regulatory memory cells than schistosomiasis only. American Fournal of Tropical Medicine and Hygiene 81, 370-370.

Mutapi, F., Burchmore, R., Mduluza, T., Foucher, A., Harcus, Y., Nicoll, G., Midzi, N., Turner, C. M. and Maizels, R. M. (2005). Praziquantel treatment of individuals exposed to Schistosoma haematobium enhances serological recognition of defined parasite antigens. Fournal of Infectious Diseases 192, 1108-1118.

Mutapi, F., Burchmore, R., Mduluza, T., Midzi, N., Turner, C. M. R. and Maizels, R. M. (2008). Age-related and infection intensity-related shifts in antibody recognition of defined protein antigens in a schistosome-exposed population. Fournal of Infectious Diseases 198, 167-175.

Mutapi, F., Hagan, P., Woolhouse, M. E. J., Mduluza, T. and Ndhlovu, P. D. (2003). Chemotherapy-induced, age-related changes in antischistosome antibody responses. Parasite Immunology 25, 87-97.

Mutapi, F., Ndhlovu, P. D., Hagan, P. and Woolhouse, M. E. (2000). Anti-schistosome antibody responses in children coinfected with malaria. Parasite Immunology 22, 207-209.

Mutapi, F., Ndhlovu, P. D., Hagan, P. and Woolhouse, M. E. J. (1997). A comparison of humoral responses to Schistosoma haematobium in areas with low and high levels of infection. Parasite Immunology 19, 255-263.

Mutapi, F., Winborn, G., Midzi, N., Taylor, M., Mduluza, T. and Maizels, R. M. (2007). Cytokine responses to Schistosoma haematobium in a Zimbabwean population: contrasting profiles for IFN-gamma, IL-4, IL-5 and IL-10 with age. BMC Infectious Diseases 7, 139.

Mwinzi, P. N. M., Karanja, D. M. S., Colley, D. G., Orago, A. S. S. and Secor, W. E. (2001). Cellular immune responses of schistosomiasis patients are altered by human immunodeficiency virus type 1 coinfection. Fournal of Infectious Diseases 184, 488-496.
Naus, C. W. A., Kimani, G., Ouma, J. H., Fulford, A. J. C., Webster, M., Van Dam, G. J., Deelder, A. M., Butterworth, A. E. and

Dunne, D. W. (1999). Development of antibody isotype responses to Schistosoma mansoni in an immunologically naive immigrant population: Influence of infection duration, infection intensity, and host age. Infection and Immunity 67, 3444-3451.

Novato-Silva, E., Gazzinelli, G. and Colley, D. G. (1992). Immune responses during human schistosomiasis mansoni. XVIII. Immunologic status of pregnant women and their neonates. Scandinavian Fournal of Immunology 35, 429-437.

Nutman, T. B. and Kumaraswami, V. (2001). Regulation of the immune response in lymphatic filariasis: perspectives on acute and chronic infection with Wuchereria bancrofti in South India. Parasite Immunology 23, 389-399.

Opara, K. N., Udoidung, N. I. and Ukpong, I. G. (2007). Genitourinary schistosomiasis among pre-primary schoolchildren in a rural community within the Cross River Basin, Nigeria. Fournal of Helminthology 81, 393-397.

Osada, Y. and Kanazawa, T. (2010). Parasitic helminths: New weapons against immunological disorders. Fournal of Biomedicine and Biotechnology 2010, 743-758.

Parkinson, J., Mitreva, M., Whitton, C., Thomson, M., Daub, J., Martin, J., Schmid, R., Hall, N., Barrell, B., Waterston, R. H., McCarter, J.P. and Blaxter, M. L. (2004). A transcriptomic analysis of the phylum Nematoda. Nature Genetics 36, 1259-1267.

Pastrana, D. V., Raghavan, N., FitzGerald, P., Eisinger, S. W., Metz, C., Bucala, R., Schleimer, R. P., Bickel, C. and Scott, A. L. (1998). Filarial nematode parasites secrete a homologue of the human cytokine macrophage migration inhibitory factor. Infection and Immunity 66, 5955-5963.

Pearce, E. J. and MacDonald, A. S. (2002). The immunobiology of schistosomiasis. Nature Reviews Immunology 2, 499-511.

Peisong, G., Mao, X. Q., Enomoto, T., Feng, Z., Gloria-Bottini, F., Bottini, E., Shirakawa, T., Sun, D. and Hopkin, J. M. (2004). An asthma-associated genetic variant of STAT6 predicts low burden of ascaris worm infestation. Genes and Immunity 5, 58-62.

Pit, D. S., Polderman, A. M., Schulz-Key, H. and Soboslay, P. T. (2000). Prenatal immune priming with helminth infections: parasite-specific cellular reactivity and Th1 and Th2 cytokine responses in neonates. Allergy 55, 732-739.

Pullan, R. L., Bethony, J. M., Geiger, S. M., Cundill, B., Correa-Oliveira, R., Quinnell, R. J. and Brooker, S. (2008). Human helminth co-infection: analysis of spatial patterns and risk factors in a brazilian community. PLoS Neglected Tropical Diseases 2, e352.

Quinnell, R. J. (2003). Genetics of susceptibility to human helminth infection. International Fournal for Parasitology 33, 1219-1231.

Quinnell, R. J., Pritchard, D. I., Raiko, A., Brown, A. P. and Shaw, M. A. (2004). Immune responses in human necatoriasis: association between interleukin-5 responses and resistance to reinfection. Fournal of Infectious Diseases 190, 430-438. 
Raso, G., Luginbuh1, A., Adjoua, C. A., Tian-Bi, N. T., Silue, K. D., Matthys, B., Vounatsou, P., Wang, Y., Dumas, M. E., Holmes, E., Singer, B. H., Tanner, M., N'Goran, E. K. and Utzinger, J. (2004). Multiple parasite infections and their relationship to self-reported morbidity in a community of rural Cote d'Ivoire. International Fournal of Epidemiology 33, 1092-1102.

Reddy, A. and Fried, B. (2007). The use of Trichuris suis and other helminth therapies to treat Crohn's disease. Parasitology Research 100, 921-927.

Redman, E., Grillo, V., Saunders, G., Packard, E., Jackson, F., Berriman, M. and Gilleard, J. S. (2008). Genetics of mating and sex determination in the parasitic nematode Haemonchus contortus. Genetics $\mathbf{1 8 0}$, 1877-1887.

Rudge, J. W., Stothard, J. R., Basanez, M. G., Mgeni, A. F., Khamis, I. S., Khamis, A. N. and Rollinson, D. (2008). Micro-epidemiology of urinary schistosomiasis in Zanzibar: Local risk factors associated with distribution of infections among schoolchildren and relevance for control. Acta Tropica $105,45-54$.

Sartono, E., Kruize, Y. C. M., Kurniawan, A., Maizels, R. M. and Yazdanbakhsh, M. (1997). Depression of antigen-specific interleukin-5 and interferon-gamma responses in human lymphatic filariasis as a function of clinical status and age. Fournal of Infectious Diseases 175, 1276-1280.

Satti, M. Z., Lind, P., Vennervald, B. J., Sulaiman, S. M., Daffalla, A. A. and Ghalib, H. W. (1996). Specific immunoglobulin measurements related to exposure and resistance to Schistosoma mansoni infection in Sudanese canal cleaners. Clinical and Experimental Immunology 106, 45-54.

Schramm, G., Falcone, F. H., Gronow, A., Haisch, K., Mamat, U., Doenhoff, M. J., Oliveira, G., Galle, J., Dahinden, C. A. and Haas, H. (2003). Molecular characterization of an interleukin-4-inducing factor from Schistosoma mansoni eggs. Fournal of Biological Chemistry 278, 18384-18392.

Scott, J. T., Turner, C. M. R., Mutapi, F., Woolhouse, M. E. J., Chandiwana, S. K., Mduluza, T., Ndhlovu, P. D. and Hagan, P. (2000). Dissociation of interleukin-4 and interleukin-5 production following treatment for Schistosoma haematobium infection in humans. Parasite Immunology 22, 341-348

Scrivener, S., Yemaneberhan, H., Zebenigus, M., Tilahun, D., Girma, S., Ali, S., McElroy, P., Custovic, A., Woodcock, A., Pritchard, D., Venn, A. and Britton, J. (2001). Independent effects of intestinal parasite infection and domestic allergen exposure on risk of wheeze in Ethiopia: a nested case-control study. Lancet 358, 1493-1499.

Secor, W. E., Karanja, D. M. S. and Colley, D. G. (2004). Interactions between schistosomiasis and human immunodeficiency virus in western Kenya. Memorias do Instituto Oswaldo Cruz 99, 93-95.

Semnani, R. T., Law, M., Kubofcik, J. and Nutman, T. B. (2004). Filaria-induced immune evasion: suppression by the infective stage of Brugia malayi at the earliest host-parasite interface. Fournal of Immunology 172, 6229-6238.
Semnani, R. T., Sabzevari, H., Iyer, R. and Nutman, T. B. (2001). Filarial antigens impair the function of human dendritic cells during differentiation. Infection and Immunity 69, 5813-5822.

Sentongo, E., Rubaale, T., Buttner, D. W. and Brattig, N. W. (1998). T cell responses in coinfection with Onchocerca volvulus and the human immunodeficiency virus type 1. Parasite Immunology 20, 431-439.

Silveira, A. M. S., Gazzinelli, G., Alves-Oliveira, L. F., Bethony, J., Gazzinelli, A., Carvalho-Queiroz, C., Alvarez, M. C. B., Lima-Silva, F. C., Prata, A., LoVerde, P. T. and Correa-Oliveira, R. (2004). Human Schistosomiasis mansoni: intensity of infection differentially affects the production of interleukin-10, interferon-gamma and interleukin-13 by soluble egg antigen or adult worm antigen stimulated cultures. Transactions of the Royal Society of Tropical Medicine and Hygiene 98, 514-519.

Smith, H. M., DeKaminsky, R. G., Niwas, S., Soto, R. J. and Jolly, P. E. (2001). Prevalence and intensity of infections of Ascaris lumbricoides and Trichuris trichiura and associated socio-demographic variables in four rural Honduran communities. Memorias do Instituto Oswaldo Cruz 96, 303-314.

Smithers, S. R. and Terry, R. J. (1967). Resistance to experimental infection with Schistosoma mansoni in rhesus monkeys induced by the transfer of adult worms. Transactions of the Royal Society of Tropical Medicine and Hygiene 61, 517-533.

Sousa-Figueiredo, J. C., Basanez, M. G., Mgeni, A. F., Khamis, I. S., Rollinson, D. and Stothard, J. R. (2008). A parasitological survey, in rural Zanzibar, of pre-school children and their mothers for urinary schistosomiasis, soil-transmitted helminthiases and malaria, with observations on the prevalence of anaemia. Annals of Tropical Medicine and Parasitology 102, 679-692.

Steel, C., Guinea, A., McCarthy, J. S. and Ottesen, E. A. (1994). Long-term effect of prenatal exposure to maternal microfilaraemia on immune responsiveness to filarial parasite antigens. Lancet 343, 890-893.

Steel, C. and Nutman, T. B. (2003). CTLA-4 in filarial infections: implications for a role in diminished $\mathrm{T}$ cell reactivity. Fournal of Immunology 170, 1930-1938.

Tchuem Tchuente, L. A., Behnke, J. M., Gilbert, F. S., Southgate, V. R. and Vercruysse, J. (2003).

Polyparasitism with Schistosoma haematobium and soiltransmitted helminth infections among school children in Loum, Cameroon. Tropical Medicine Eீ International Health 8, 975-986.

Tingley, G. A., Butterworth, A. E., Anderson, R. M., Kariuki, H. C., Koech, D., Mugambi, M., Ouma, J. H., Siongok, T. K. A. and Sturrock, R. F. (1988). Predisposition of humans to infection with Schistosoma mansoni-evidence from the reinfection of individuals following chemotherapy. Transactions of the Royal Society of Tropical Medicine and Hygiene 82, 448-452.

Trottein, F., Godin, C., Pierce, R. J., Sellin, B., Taylor, M. G., Gorillot, I., Silva, M. S., Lecocq, J. P. and Capron, A. (1992). Interspecies variation of 
schistosome 28-Kda glutathione-S-transferases. Molecular and Biochemical Parasitology 54, 63-72.

Trpis, M. (2006). Consequences of vector behaviour in epidemiology of onchocerciasis on the Firestone Rubber Plantation in Liberia. American Fournal of Tropical Medicine and Hygiene 74, 833-840.

Turaga, P. S. D., Tierney, T. J., Bennett, K. E., McCarthy, M. C., Simonek, S. C., Enyong, P. A., Moukatte, D. W. and Lustigman, S. (2000). Immunity to onchocerciasis: cells from putatively immune individuals produce enhanced levels of interleukin-5, gamma interferon, and granulocytemacrophage colony-stimulating factor in response to Onchocerca volvulus larval and male worm antigens. Infection and Immunity 68, 1905-1911.

Turner, J. D., Faulkner, H., Kamgno, J., Cormont, F., Van Snick, J., Else, K. J., Grencis, R. K., Behnke, J. M., Boussinesq, M. and Bradley, J. E. (2003). Th2 cytokines are associated with reduced worm burdens in a human intestinal helminth infection. Fournal of Infectious Diseases 188, 1768-1775.

Veldhoen, M., Uyttenhove, C., Van Snick, J., Helmby, H., Westendorf, A., Buer, J., Martin, B., Wilhelm, C. and Stockinger, B. (2008). Transforming growth factor-beta 'reprograms' the differentiation of T helper 2 cells and promotes an interleukin 9-producing subset. Nature Immunology 9, 1341-1346.

Vermund, S. H., Bradley, D. J. and Ruiztiben, E. (1983). Survival of Schistosoma mansoni in the human host-estimates from a community-based prospective-study in Puerto-Rico. American Journal of Tropical Medicine and Hygiene 32, 1040-1048.

Viana, I. R., Sher, A., Carvalho, O. S., Massara, C. L., Eloi-Santos, S. M., Pearce, E. J., Colley, D. G., Gazzinelli, G. and Correa-Oliveira, R. (1994). Interferon-gamma production by peripheral blood mononuclear cells from residents of an area endemic for Schistosoma mansoni. Transactions of the Royal Society of Tropical Medicine and Hygiene 88, 466-470.

Viana, I. R. C., CorreaOliveira, R., Dossantos, O., Massara, C. L., Colosimo, E., Colley, D. G. and Gazzinelli, G. (1995). Comparison of antibody isotype responses to Schistosoma mansoni antigens by infected and putative resistant individuals living in an endemic area. Parasite Immunology 17, 297-304.

Watanabe, K., Mwinzi, P. N., Black, C. L., Muok, E. M., Karanja, D. M., Secor, W. E. and Colley, D. G. (2007). T regulatory cell levels decrease in people infected with Schistosoma mansoni on effective treatment. American Fournal of Tropical Medicine and Hygiene 77, 676-682.

Webster, M., CorreaOliveira, R., Gazzinelli, G., Viana, I. R. C., Fraga, L. A. D., Silveira, M. S. and Dunne, D. W. (1997). Factors affecting high and low human $\mathrm{IgE}$ responses to schistosome worm antigens in an area of Brazil endemic for Schistosoma mansoni and hookworm. American Fournal of Tropical Medicine and Hygiene 57, 487-494.

Williams-Blangero, S., McGarvey, S. T., Subedi, J., Wiest, P. M., Upadhayay, R. P., Rai, D. R., Jha, B., Olds, G. R., Wu, G. L. and Blangero, J. (2002a).
Genetic component to susceptibility to Trichuris trichiura: Evidence from two Asian populations. Genetic Epidemiology 22, 254-264.

Williams-Blangero, S., VandeBerg, J. L., Subedi, J., Aivaliotis, M. J., Rai, D. R., Upadhayay, R. P., Jha, B. and Blangero, J. (2002b). Genes on chromosomes 1 and 13 have significant effects on Ascaris infection. Proceedings of the National Academy of Sciences, USA 99, 5533-5538.

Williams, M. E., Montenegro, S., Domingues, A. L., Wynn, T. A., Teixeira, K., Mahanty, S., Coutinho, A. and Sher, A. (1994). Leukocytes of patients with Schistosoma mansoni respond with a Th2 pattern of cytokine production to mitogen or egg antigens but with a Th0 pattern to worm antigens. Fournal of Infectious Diseases 170, 946-954.

Wilson, S., Jones, F. M., Mwatha, J. K., Kimani, G., Booth, M., Kariuki, H. C., Vennervald, B. J., Ouma, J. H., Muchiri, E. and Dunne, D. W. (2008). Hepatosplenomegaly is associated with low regulatory and Th2 responses to schistosome antigens in childhood schistosomiasis and malaria coinfection. Infection and Immunity 76, 2212-2218.

Woolhouse, M. E. J. (1998). Patterns in parasite epidemiology: the peak shift. Parasitology Today 14, 428-434.

Woolhouse, M. E. J. and Hagan, P. (1999). Seeking the ghost of worms past. Nature Medicine 5, 1225-1227.

Wynn, T. A., Oswald, I. P., Eltoum, I. A., Caspar, P., Lowenstein, C. J., Lewis, F. A., James, S. L. and Sher, A. (1994). Elevated expression of Th1 cytokines and nitric-oxide synthase in the lungs of vaccinated mice after challenge infection with Schistosoma mansoni. Fournal of Immunology 153, 5200-5209.

Yazdanbakhsh, M. and Sacks, D. L. (2010). Why does immunity to parasites take so long to develop? Nature Reviews Immunology 10, 80-81.

Zhang, W. B., Ross, A. G. and McManus, D. P. (2008). Mechanisms of immunity in hydatid disease: Implications for vaccine development. Fournal of Immunology 181, 6679-6685.

Zhou, Y., Zheng, H. J., Chen, Y. Y., Zhang, L., Wang, K., Guo, J., Huang, Z., Zhang, B., Huang, W., Jin, K., Dou, T. H., Hasegawa, M., Wang, L., Zhang, Y., Zhou, J., Tao, L., Cao, Z. W., Li, Y.X., Vinar, T., Brejova, B., Brown, D., Li, M., Miller, D. J., Blair, D., Zhong, Y., Chen, Z., Hu, W., Wang, Z. Q., Zhang, Q. H., Song, H. D., Chen, S. J., Xu, X. N., Xu, B., Ju, C., Huang, Y. C., Brindley, P. J., McManus, D. P., Feng, Z., Han, Z. G., Lu, G., Ren, S. X., Wang, Y. Z., Gu, W. Y., Kang, H., Chen, J., Chen, X. Y., Chen, S. T., Wang, L. J., Yan, J., Wang, B. Y., Lv, X. Y., Jin, L., Wang, B. F., Pu, S. Y., Zhang, X. L., Zhang, W., Hu, Q.P., Zhu, G. F., Wang, J., Yu, J., Wang, J., Yang, H. M., Ning, Z. M., Beriman, M., Wei, C. L., Ruan, Y. J., Zhao, G. P., Wang, S. Y., Liu, F., Wang, Z. Q., Zheng, H. J., Zhang, Q. H., Wang, S. Y., Han, Z. G. and Seque, S. J. G. (2009). The Schistosoma japonicum genome reveals features of host-parasite interplay. Nature, London 460, 345-U356. 